\title{
Dual Role of Autophagy in Diseases of the Central Nervous System
}

\author{
Tamara Bar-Yoseft, Odeya Damrit and Galila Agam* \\ Department of Clinical Biochemistry and Pharmacology and Psychiatry Research Unit, Faculty of Health Sciences, \\ Ben-Gurion University of the Negev and Mental Health Center, Beersheba, Israel
}

\section{OPEN ACCESS}

Edited by:

Pier Giorgio Mastroberardino, Erasmus University Rotterdam,

Netherlands

Reviewed by: Sandra Moreno,

Roma Tre University, Italy Alessandro Simonati,

University of Verona, Italy

*Correspondence: Galila Agam galila@bgu.ac.il

tThese authors have contributed equally to this work

Specialty section:

This article was submitted to Cellular Neuropathology,

a section of the journal

Frontiers in Cellular Neuroscience

Received: 13 November 2018 Accepted: 18 April 2019

Published: 28 May 2019

Citation:

Bar-Yosef T, Damri O and Agam G (2019) Dual Role of Autophagy in Diseases of the Central Nervous System. Front. Cell. Neurosci. 13:196. doi: 10.3389/fncel.2019.00196
Autophagy is a vital lysosomal degradation and recycling pathway in the eukaryotic cell, responsible for maintaining an intricate balance between cell survival and cell death, necessary for neuronal survival and function. This dual role played by autophagy raises the question whether this process is a protective or a destructive pathway, the contributor of neuronal cell death or a failed attempt to repair aberrant processes? Deregulated autophagy at different steps of the pathway, whether excessive or downregulated, has been proposed to be associated with neurodegenerative disorders such as Alzheimer's-, Huntington's-, and Parkinson's-disease, known for their intracellular accumulation of protein aggregates. Recent observations of impaired autophagy also appeared in psychiatric disorders such as schizophrenia and bipolar disorder suggesting an additional contribution to the pathophysiology of mental illness. Here we review the current understanding of autophagy's role in various neuropsychiatric disorders and, hitherto, the prevailing new potential autophagy-related therapeutic strategies for their treatment.

Keywords: autophagy, central nervous system, neurodegenerative diseases, psychiatric disorders, lithium

\section{INTRODUCTION}

Autophagy is an essential process by which cytoplasmic molecules (proteins, lipids, nucleic acids, and polysaccharides) (Farre and Subramani, 2004; Uttenweiler and Mayer, 2008) and subcellular organelles such as mitochondria (mitophagy) (Farre et al., 2009; Kiel, 2010) are delivered to the lysosome for degradation and recycling. It is an evolutionarily conserved pathway occurring in eukaryotic cells. It is induced under stress conditions such as absence of growth factors, low oxygen levels, or nutrient starvation (Levine and Klionsky, 2004; Wang et al., 2006; Williams et al., 2006; Mazure and Pouyssegur, 2010) assuring cell survival. It is also required for development, differentiation, homeostasis and, in specific conditions, cell death (Levine and Kroemer, 2008; Martinet et al., 2009; Wu et al., 2015). The three forms of autophagy are: macroautophagy the main pathway designated autophagy, microautophagy, and chaperone-mediated autophagy (CMA; Hu et al., 2015; Wu et al., 2015). In autophagy cytosolic double-membrane structures autophagosomes - are formed. They sequester protein aggregates, damaged organelles, and microbes (Perrotta et al., 2015), moving along microtubules toward microtubule-organizing center (Jahreiss et al., 2008), subsequently fusing with the lysosome to form autolysosomes where degradation and recycling by acidic lysosomal hydrolases takes place (Wang et al., 2006; Puyal et al., 2012).

The main autophagy signaling is regulated by the mTOR pathway, essential for cell growth and protein synthesis among many other cellular pathways (Guertin and Sabatini, 2009). There are 
two mTOR complexes: mTOR complex 1 (mTORC1) and mTOR complex 2 (mTORC2) (Guertin and Sabatini, 2009). The mechanism(s) via which mTORC1 regulates autophagy are (is) currently unclear (Thoreen et al., 2009). In response to growth factors signaling (insulin in particular) and to elevated nutrient levels, conditions which inhibit AMP-dependent kinase (AMPK; Meijer and Codogno, 2006; Cheong and Klionsky, 2014) mTOR suppresses autophagy. The most known pathway of upregulating autophagy is via the lipophilic antibiotic rapamycin, inactivating mTOR. Down-regulation of mTOR through rapamycin prevented mitochondrial-dependent apoptosis and resulted in the activation of autophagy (Ravikumar et al., 2004; Eisenberg-Lerner et al., 2009; Nikoletopoulou et al., 2013). Pre-treatment with rapamycin has been shown to protect cell lines from pro-apoptotic insults in an autophagy-dependent way (Ravikumar et al., 2006). These protective effects suggest that autophagy may protect from cell death (Williams et al., 2006). However, rapamycin treatment does not affect autophagosome dynamics (movement), so clearance by autophagy induction is likely because of the increase in autophagosome formation (Jahreiss et al., 2008). Others autophagy mediators include the autophagy-related genes (ATG), conserved from yeast to mammals, and the microtubule-associated protein 1A/1B-light chain 3 (LC3), a protein family comprised of LC3, LC3A, and LC3B. During autophagosomes engulfment LC3 is cleaved to LC3-I and converted by phosphatidylethanolamine to LC3-II. The latter is recruited to autophagosomal membranes (Tanida et al., 2008). LC3-II, a mammalian homolog of Atg8, is the best known autophagosome-specific protein marker (Mizushima, 2007) presented inside and outside of the autophagosomes. Its amount correlates with the size of the autophagosomes (Kabeya et al., 2000). p62/sequestosome 1 is a protein complex that when binding with LC3-interacting region (LIR; Lim et al., 2011) can localize to autophagic compartments transporting ubiquitinated proteins for degradation. This process is important for autophagic vacuoles (AVs) containing specific cargo (Kirkin et al., 2009). The protein Beclin1 is another regulator (the mammalian ortholog of the yeast Atg6/Vps30 gene). It interacts with $\mathrm{B}$-cell lymphoma 2 (Bcl-2)-like proteins to form a complex. The complex is a key regulator of autophagy. Namely, its modulation either stimulates or inhibits this cellular pathway (Cao and Klionsky, 2007; He and Levine, 2010). In microautophagy cytoplasmic content is delivered into the lysosome by invagination of the lysosomal membrane into its lumen. Overall, the molecular mechanism of microautophagy regulation is still unclear (Hu et al., 2015). In the CMA pathway, activated during cellular hypoxic and ischemic stress, chaperones selectively transfer cytosolic protein aggregates into the lysosome for degradation. This occurs without vesicle formation (Dohi et al., 2012; Wu et al., 2015).

Autophagy dysfunction has previously been associated with a variety of diseases such as cancer (Gozuacik and Kimchi, 2004), muscular disorders (Danon's disease) (Nishino et al., 2000), pathogen infections (Listeria monocytogenes) (Shintani and Klionsky, 2004), cerebral ischemia (Wei et al., 2012), neurodegeneration (Wong and Cuervo, 2010; Puyal et al., 2012; Wei et al., 2012), psychiatric disorders (Kara et al., 2013;
Jia and Le, 2015; Yuan et al., 2015), and more. This review will focus on autophagy and its dual role - in cell survival and in cell death in the central nervous system (CNS), namely, in neurodegenerative [Alzheimer's disease (AD), Parkinson's disease (PD), and Huntington's disease (HD) (Wu et al., 2015)] and psychiatric [schizophrenia (Yuan et al., 2015), bipolar disorder (BPD) (O'Shea and McInnis, 2015), and unipolar depression (Jia and Le, 2015)].

Post-mortem brain studies which found accumulation of autophagosome-like vesicles in axonal terminals of dysfunctional or degenerating neurons (Yue, 2014) in neurodegenerative disease patients (Yamamoto and Yue, 2014), deviated expression of autophagy-related proteins in schizophrenia patients (Merenlender-Wagner et al., 2014) along with studies indicating that autophagy enhancers induce an anti-depressant-like effect (Cleary et al., 2008; Kara et al., 2013; Jia and Le, 2015) implicate the involvement of aberrant autophagy in the pathogenesis of these disorders and suggest that enhancing the process protects against them (Levine and Kroemer, 2008).

\section{AUTOPHAGY AND NEURODEGENERATIVE DISORDERS}

Autophagy in the CNS is constitutively active (Komatsu et al., 2006), maintaining an important housekeeping role by eliminating defective proteins and organelles, preventing the accumulation of aggregates, providing energy demands, and supporting neuronal plasticity (Wang et al., 2006; Fimia et al., 2007; Komatsu et al., 2007). Evidence indicates that autophagy plays a neuroprotective role (Puyal et al., 2012). This role is particularly important in post-mitotic cells including neurons in order to protect against neurodegeneration and to promote cell survival (Levine and Kroemer, 2008; Nikoletopoulou et al., 2013). The neuronal soma exhibits basal levels of autophagy, mitophagy, and CMA, maintaining cellular homeostasis. Axon injuries induce accumulation of autophagosomes or AVs and dystrophic axonal swellings. Synapses require high energy and protein turnover. Therefore they are more vulnerable to autophagy dysfunction (Son et al., 2012).

On the other hand, autophagy has been associated with promotion of cell death (type-II cell death) as a result of circumstances such as excessive activation of autophagy [e.g., overexpression of the Atg1 in Drosophila (Scott et al., 2007), requirement for massive cell elimination and neuronal excitotoxicity (Clarke, 1990; Komatsu et al., 2006; Ginet et al., 2009)]. It is possible that excessive up-regulation of autophagy and long-term autophagy up-regulation eventually result in selfdigestion or have harmful effects (Martinet et al., 2009; Renna et al., 2010; Puyal et al., 2012). The role of autophagy in cell death and the detailed mechanism are still unclear and it is under debate whether type-II cell death is apoptosis-related or is a separate process (Kroemer and Levine, 2008; Levine and Kroemer, 2008; Puyal and Clarke, 2009). Interestingly, apoptosis and autophagy share regulators such as Beclin1, Bcl-2, p53, and Atg5 which may interact to promote neuronal cell death (Xue et al., 1999; Mizushima et al., 2008). Beclin1 has been linked to protection 
against neurodegenerative diseases and to lifespan extension (He and Levine, 2010).

Protein aggregates are a result of defective protein production that can be caused by oxidative stress, ultraviolet radiation, toxic compounds, genetic mutations, post-translational modifications and more (Markossian and Kurganov, 2004). The soluble forms are targeted for degradation via the CMA or the ubiquitin-proteasome pathways (UPS). The insoluble forms of the proteins form complex structures (oligomers and fibrils) making it difficult to traverse through the proteasome's pore (Verhoef et al., 2002) or to be degraded by the CMA pathway (Levine and Kroemer, 2008). In these instances autophagy is activated (Rubinsztein et al., 2005). However, when autophagy and other protein degradation systems are impaired/altered, neurons display accumulation of defective or mutant protein aggregates (Ross and Poirier, 2004) leading to a toxic effect of cellular damage and ultimately to cell death associated with neurodegeneration (Hara et al., 2006; Komatsu et al., 2006; Levine and Kroemer, 2008; Nikoletopoulou et al., 2013). Indeed, blockade of autophagy in Atg5- and Atg7-deficient mice lead to the appearance of inclusion bodies accumulated in the cerebral cortex and the cerebellum, neurodegeneration and loss of neurons (Hara et al., 2006; Komatsu et al., 2006).

Presence of excessive accumulation of autophagy vesicles (autophagosomes and lysosomes) has been observed in postmortem brain of patients with $\mathrm{AD}, \mathrm{PD}$ and $\mathrm{HD}$ (Rubinsztein et al., 2005, 2007; Williams et al., 2006) raising the question whether the accumulation of these vesicles is a result of autophagy dysfunction (Martinez-Vicente and Cuervo, 2007; Rubinsztein et al., 2007) or due to excessive autophagy (Shintani and Klionsky, 2004).

\section{Alzheimer's Disease}

Alzheimer's disease, the most common neurodegenerative disorder (Alzheimer's, 2016; Liu et al., 2018), is defined by memory loss and a decline in cognitive functions (Terry and Davies, 1980). It is characterized by progressive loss of neurons due to two pathologic lesions: (i) senile plaques consisting of extracellular $\beta$-amyloid $(\mathrm{A} \beta)$ deposit scattered among axons and dendrites. The plaques are derived from amyloid-precursor protein (APP) proteolysis (Yu et al., 2005; Martinet et al., 2009) with an unclear biological function (Nixon, 2007); (ii) neurofibrillary tangles composed mainly of tau-proteins that are abnormally phosphorylated and aggregated into filaments inside the neurons (Nixon, 2007).

As recently reviewed ( $\mathrm{Li}$ et al., 2017; Moloudizargari et al., 2017) dysfunctional autophagy is implied in AD's pathogenesis. Evidence shows impaired maturation or fusion of autophagosomes with lysosomes or their transport toward the neuronal cell body. Endosomal-lysosomal dysfunction has also been presented as accumulation of AVs containing $A \beta$ within dystrophic neurons and dendrites (neurites) in post-mortem human brain and in a mouse model of AD (Nixon et al., 2005; Yu et al., 2005). It is unclear whether this reflects defective AVs clearance due to impaired autophagosomes-lysosomal fusion or due to enhanced autophagy (Rubinsztein et al., 2005). Inhibition of dynein function in PC12 cells [dyneins are microtubule-based motor proteins responsible for the movement of cargo from the distal ends of axons to the cell bodies of neurons (Goldstein and Yang, 2000)] impaired the process and slowed clearance of proteins proned to aggregate (e.g., A53T $\alpha$-synuclein) (Ravikumar et al., 2005). A study in mouse blastocysts has shown that a mutation in the presenilin-1 gene (PS1) caused lack of clearance by autophagy and might account, at least partly, for protein accumulation in AD. PS1 is required for lysosomal turnover of autophagic and endocytic protein substrates. PS1 deletion caused loss of autophagy function due to impaired autolysosome acidification and cathepsin activation [cysteine cathepsins are proteases responsible for proteolytic degradation within the lysosome (Stoka et al., 2016)] (Lee et al., 2010). Accordingly, enhancing lysosomal cathepsin activity in an AD mouse model reduced the accumulation of $A \beta$, ubiquitinated proteins and other autophagic substrates within autolysosomeslysosomes, and decreased extracellular and total brain amyloid deposition (Yang et al., 2011). Overall, these studies present prominent lysosomal dysfunction in AD (Whyte et al., 2017). In $\mathrm{AD}$ mice models autophagosome presence in dendrites increases before deposits are created, indicating autophagy as a primary response and not as an outcome of deposit formation (Nixon, 2007). It is suggested to be a prior event of the abnormally accumulation of AV's. Furthermore, APP, PS1 and other substrates necessary for the generation of $A \beta$ peptides were identified in isolated AVs of AD mice models livers ( $\mathrm{Yu}$ et al., 2004), suggesting potential AVs' role in $A \beta$ generation (Yu et al., 2005).

Long-term inhibition of mTOR by rapamycin administration (to increase autophagy) prevented $\mathrm{AD}$-like cognitive deficits and lowered A $\beta$ levels (Spilman et al., 2010). A study in AD patients' mid-frontal cortex gray matter found reduction of beclin1 protein levels. Inducing haploinsufficiency of the beclin1 gene in mice decreased neuronal autophagy and led to neurodegeneration and lysosome disturbance. Moreover, in an $\mathrm{AD}$ mouse model, reduction of beclin1 expression resulted in increased intraneuronal and extracellular $A \beta$ accumulation, substantial neuronal abnormalities and neurodegeneration (Pickford et al., 2008). According to evidence presented above of gradually impaired autophagy seen as autophagic-lysosomal dysfunction and the loss of proteasome activity (Keller et al., 2000), neurons are left without a coping mechanism against toxic protein accumulation and there is a sense in restoring normal autophagy as a therapeutic strategy.

A vicious circle, in which neuronal mitochondrial dysfunction, apparently due to impaired mitophagy occurring early in the disease development and resulting in oxidative damage and cellular energy deficits which, in turn, further impair mitophagy has also been recently suggested to promote $\mathrm{A} \beta$ and Tau pathologies (Simoncini et al., 2015).

\section{Huntington's Disease}

Huntington's disease is an inherited autosomal dominant disease (Martin and Gusella, 1986) characterized by insoluble aggregation of an abnormally long polyglutamine (also called inclusions) caused by a gain-of-function mutation in the huntingtin gene (The Huntington's Disease Collaborative 
Research Group, 1993; Gil and Rego, 2008). This accumulation leads to progressive memory loss, cognitive decline, impaired movement and more (Martin and Gusella, 1986). The mutation is expressed by expansion of cytosine-adenine-guanine (CAG) repeats at the $\mathrm{N}$-terminus of the huntingtin gene. This condition contributes to slow progressive neuronal loss in the striatum and cortex that leads to death. The onset age is between 35 and 50 years and it is a progressive disease with clinical manifestations such as motor disturbances, cognitive decline, bradykinesia, rigidity, muscle wasting, weight loss, and eventually death (Gil and Rego, 2008). Diverse mechanisms such as apoptosis, oxidative stress and mitochondrial dysfunction have been implicated in HD pathophysiology (Gil and Rego, 2008). In addition, studies suggest that autophagy plays a central role in the progressive degeneration of HD (Martinet et al., 2009). Indeed, observations in HD mouse models and in cells from humans with HD identified a specific autophagic defect in which the ability of AVs to recognize and trap cytosolic cargo is compromized (Martinez-Vicente et al., 2010).

Huntington's disease mouse models show that the ubiquitinproteasome system tends to become overloaded with the increasing number of aggregates and this impairment activates cell death pathways through apoptosis or autophagy (Iwata et al., 2005). Expression of mutated huntingtin causes endosomallysosomal activity (Kegel et al., 2000) and HD brains display endosomal-lysosomal organelle accumulation (Tellez-Nagel et al., 1974; Sapp et al., 1999). Also, it has been shown that the number of AVs in lymphoblasts of HD patients correlated with the length of the polyglutamine expansion (Nagata et al., 2004).

Autophagy may be the cell's way to eliminate the huntingtin mutants. It has been reported that abolishing huntingtin mutant expression in mice models of $\mathrm{HD}$ prevents symptoms of progression and may reverse aggregate formation and progressive motor decline (Yamamoto et al., 2000). Also, stimulation of autophagy in clonal striatal cells, PC12 cells and rodent embryonic cells promoted degradation of huntingtin whereas blocking autophagy reduced cell viability and increased the number of cells containing aggregates of mutant huntingtin (Qin et al., 2003). Over-expression of the transcription factor TFEB (transcription factor $\mathrm{EB}$ ) in the striatum of $\mathrm{HD}$-mutant mice stimulated autophagy and lysosome activity and lowered mutant huntigtin levels (Vodicka et al., 2016). Another study supporting this observation has shown increased autophagy only in HD model cells expressing mutant aggregates and demonstrated that treatment with rapamycin or its analog CCI-779 in fly and mouse models reduced aggregate formation and cell death and presented improvements in phenotypes related to neurological dysfunction (Ravikumar et al., 2004). Yet, rapamycin's mTOR activity inhibition might be impaired following long huntingtin expression or increased formation of its aggregates probably due to mTOR sequestration in inclusions resulting in lower levels of soluble mTOR (Ravikumar et al., 2002, 2004).

Studies have revealed that if the production of the aggregates is halted the cells have the ability to clear them. In a study that exemplifies this notion autophagy triggered clearance through the activation of beclin1 and Vps34 promoted by insulin receptor substrate 2 , despite activation of Akt and mTOR. This implies an mTOR-independent autophagy activation (Yamamoto et al., 2006). However, accumulated mutant huntingtin recruits Beclin1 impairing its activity thereby reducing autophagic degradation. The mechanism of the latter process has recently been uncovered by Ashkenazi et al. (2017). They demonstrated that the activity of ataxin-3 (which interacts with beclin 1 allowing its deubiquitinase activity to protect beclin 1 from proteasomemediated degradation enabling autophagy) mediated by its polyQ domain was competed by other soluble proteins with polyQ tracts in a length-dependent fashion. In cells expressing mutant huntingtin exon 1, in brain of HD mouse model and in HD patient cells this resulted in impaired starvation-induced autophagy. They also observed decreased beclin 1 levels and impaired starvation-induced autophagy in fibroblasts derived from HD patients, compared to controls. Furthermore, in human brains beclin1's expression declines with age which may result in parallel reduction in autophagic activity (Shibata et al., 2006).

\section{Parkinson's Disease}

Parkinson's disease is characterized by tremors, muscular rigidity, and bradykinesia caused by progressive loss of dopaminergic neurons in the substantia nigra pars compacta (SNpc) followed by accumulation of mutant protein inclusions in Lewy bodies (Gelb et al., 1999). Interestingly, mutations in different subtypes of PD can affect different stages of autophagy (Karabiyik et al., 2017). In familial PD accumulation of mutant $\alpha$-synuclein (A53T and A30P) in the Lewy bodies is implicated in the disease pathogenesis (Duda et al., 2002; Cuervo et al., 2004). Wild-type $\alpha$-synuclein, a protein of unknown function, is implied as a pre-synaptic regulator of dopamine neurotransmission (Abeliovich et al., 2000) and is normally translocated into lysosomes for CMA degradation (Webb et al., 2003; Cuervo et al., 2004). The pathogenic $\alpha$-synuclein mutants bind to the lamp2a receptor located on the lysosomal membrane acting as uptake blockers thereby inhibiting their own and other substrates' degradation, resulting in an up regulation of autophagy as a compensatory response (Martinet et al., 2009). It has been shown that autophagy plays a role in the degradation of the $\alpha$-synuclein mutants (Webb et al., 2003). Accordingly, lysosomelike vacuoles were observed in the dopaminergic neurons of the SNpc of PD patients (Anglade et al., 1997; Zhu et al., 2003). Inhibition of autophagy by $\alpha$-synuclein over-expression has been shown to result in mislocalization of the autophagy protein Atg9 and to decrease autophagosome precursors formation (Winslow et al., 2010).

Another mutated gene that has been linked to PD is the loss-of-function Park2, coding for the ubiquitin-ligase parkin. In mammalian cells parkin is recruited to dysfunctional mitochondria exhibiting low membrane potential mediating the engulfment of mitochondria by autophagosomes. Mutations in this gene result in failure to eliminate dysfunctional mitochondria, implying autophagic and mitochondrial dysfunction in the pathogenesis of PD (Narendra et al., 2008). In a recent review Beilina and Cookson (Beilina and Cookson, 2016) discuss the relationships between protein products of PD genes and indicate their links with regulation of the autophagy-lysosome system attesting that such an interaction 
only exists for some of the genes. Similarly, Beneto et al. (2016) propose that the ATP13A2 gene (mutated in some types of early-onset Parkinsonism) and the SYT11 gene (associated with $\mathrm{PD}$, the transcription of which is regulated by ATP13A2) comprize a regulation network of the autophagy-lysosome pathway. To sum-up, the autophagy-lysosome pathway in $\mathrm{PD}$ might be the neurons' attempt to compensate dysfunctional degradation pathways that backfire, causing further damage to the cell, eventually leading toward cell death, thus contributing to $\mathrm{PD}$-associated neurodegeneration. However, perplexing data have recently been described. Based on the report that microRNA (miR)-181a is downregulated in PD (Ding et al., 2016), Liu et al. (2017) overexpressed miR-181a in MPP-treated human neuroblastoma cells (an accepted PD-like model). It resulted in a significant decrease of the expression of the autophagy markers LC3II/LC3I ratio and Beclin1, but also in attenuated cell apoptosis.

\section{AUTOPHAGY AND PSYCHIATRIC DISORDERS}

\section{Schizophrenia}

Schizophrenia is a mental disorder with a prevalence of $1 \%$ in the population characterized by positive (e.g., disturbed thoughts and perception, delusions, and hallucinations) and negative (e.g., diminished emotional expression and motivation) symptoms, disorganized thinking, cognitive and emotional decline, severe reduction in social functioning and hampered coping abilities (Perala et al., 2007; Rezin et al., 2009; Tandon et al., 2013; Yuan et al., 2015). The onset mostly occurs at late adolescence (Perala et al., 2007; Rezin et al., 2009). The etiology is unknown, but it appears to have developmental changes at synapses among other sites (Perala et al., 2007; Balu and Coyle, 2011). Autophagy is suggested to have a key role in the pathophysiology of schizophrenia (Merenlender-Wagner et al., 2014, 2015; Yuan et al., 2015). Beclin1 mRNA levels were reported to be $40 \%$ reduced in post-mortem hippocampal samples of schizophrenia patients compared to control subjects (Merenlender-Wagner et al., 2015). Similarly, reduced Beclin $1 \mathrm{mRNA}$ and protein levels and decreased LC3-II levels were found in the hippocampus of schizophrenia mouse models (Merenlender-Wagner et al., 2014; Yuan et al., 2015).

Schizophrenia, originally named "dementia praecox" and AD share similarities and it is suggested that neurodegeneration also plays a role in the pathophysiology of schizophrenia (Lieberman, 1999; Horesh et al., 2011). Both disorders share gene expression changes in the superior temporal gyrus including downregulation of autophagy-related genes such as beclin1 and ATG3 (Horesh et al., 2011). This may suggest that autophagy dysfunction is shared by both disorders, although their underlying neurobiology is different.

Activity-dependent neuroprotective protein (ADNP) is necessary for brain formation, development, neuroprotection, and plasticity. The protein directly interacts with LC3II, suggesting its role in autophagy (Bassan et al., 1999; MerenlenderWagner et al., 2015). $\mathrm{ADNP}^{+/-}$mice exhibited cognitive dysfunction, increased tau hyper-phosphorylation and memory impairment, tangle-like structures and neurodegeneration reminiscent of AD (Vulih-Shultzman et al., 2007). Our group has demonstrated that "disturbance of ADNP in schizophrenia has a negative effect on autophagic activity; ADNP and ADNP2 (homologous protein of ADNP) expression was deregulated in post-mortem hippocampus of schizophrenia patients compared to healthy matched controls and the deregulation correlated with the disease progression" (Dresner et al., 2011; MerenlenderWagner et al., 2015). We argued that "increased ADNP and ADNP2 expression in lymphocytes from schizophrenia patients compared to healthy controls and a negative correlation with disease duration may be a compensatory mechanism. Additionally, beclin 1 mRNA levels was decreased by $\sim 20 \%$ in the $\mathrm{ADNP}^{+/-}$mouse hippocampus, coupled to $\sim 30 \%$ increase in $\mathrm{Bcl} 2$, suggesting an impact of ADNP deregulation on brain autophagy" (Merenlender-Wagner et al., 2015). Interestingly, administration of the peptide sequence NAP (NAPVSIPQ), derived from ADNP, inhibited apoptosis (Leker et al., 2002; Gozes and Divinski, 2007), enhanced ADNP-LC3-II interaction (Merenlender-Wagner et al., 2014), reversed the decrease in hippocampal Beclin1 mRNA levels in a mouse model of schizophrenia (MAP6-deficiency) and decreased cognitive deficits and tau hyperphosphorylation in $\mathrm{ADNP}^{+/-}$mice (VulihShultzman et al., 2007). NAP also decreased schizophrenia-like hyperactivity in a different mouse model of schizophrenia (Merenlender-Wagner et al., 2010). Phencyclidine (PCP), a noncompetitive antagonist of glutamatergic $N$-methyl-D-aspartate receptor, induces positive- and negative-like signs exhibited by schizophrenia patients (Javitt et al., 2012).

Recently, Jevtic et al. (2016) used the PCP-induced schizophrenia-like behavior in perinatal rats and reported alterations in autophagy markers.

Another indication for the possible involvement of aberrant autophagy in schizophrenia relates to the apolipoprotein L1 (ApoL1) gene. Overexpression of ApoL1 induces autophagic cell death (Zhaorigetu et al., 2008) and expression of ApoL1 was found to be significantly upregulated in post-mortem brain of schizophrenia patients (Mimmack et al., 2002). Moreover, in humans, the ApoL1 gene is localized to chromosome 22q13.1, a region with loci suggested to be linked to susceptibility to schizophrenia (Takahashi et al., 2008). Observation of reduced Beclin 1 in post-mortem brains of schizophrenia patients and mouse models could indicate autophagy's link to the pathogenesis of the illness.

\section{Bipolar Disorder}

Bipolar disorders (Belmaker, 2004) are a group of mental disorders with high heritability (McGuffin et al., 2003; Kieseppa et al., 2004) and estimated life-time risk of $1-2 \%$ in the adult population. BPDs are characterized by mood swings between depression and mania (Manji and Lenox, 1998) resulting in hampered functioning, impaired cognition and disrupted life of the patients and their families (Zarate et al., 2006a. The manic phase is defined by a "hyper" state, enhanced motor activity, improper judgment, racing thoughts and decreased sleep. The depressive phase is defined by major depression symptoms, such 
as depressed mood, cognitive changes, psychomotor changes, and more (Goodwin and Jamison, 1990; Gould et al., 2004). The etiology/pathophysiology of the illnesses is still unknown but accumulating data point at brain mitochondrial dysfunction as a central characteristic of BPDs (Scaini et al., 2016). Toker and Agam (2015) suggested that disturbed mitochondrial function in BPD is a result of impaired autophagy.

Searching for studies linking autophagy with BPD yielded very few indirect results, dealing, mostly, with mood stabilizers, and autophagy (see section "The potential of autophagy-related therapeutic strategies for the treatment of neurodegenerative and psychiatric disorders").

\section{Major Depression Disorder}

Major depressive disorder (MDD) is a mental illness characterized by depressed mood, decreased interest or pleasure in most activities, low energy or fatigue, sleep disturbances and more (Belmaker and Agam, 2008; Eshel and Roiser, 2010; American Psychiatric Association, 2016). This condition has an overall lifetime prevalence of up to 17\% (Larsen et al., 2010) with a significant effect on the quality of life, high rates of morbidity and mortality and an enormous economic burden on the society (Wang et al., 2003). The pathogenesis of MDD is yet unknown although some hypotheses such as dysfunction of synaptic plasticity (Wainwright and Galea, 2013; Kuhn et al., 2014), increased apoptosis (Shelton et al., 2011; Miguel-Hidalgo et al., 2014) and aberrant autophagy (Gassen et al., 2015; Jia and Le, 2015) prevail.

Some studies have implicated deficits in the mTOR signaling system in MDD. mTOR protein levels were reported to be reduced in post-mortem prefrontal cortex of MDD patients (Jernigan et al., 2011). Chronic stress is frequently used to model MDD in rodents. In the amygdala of rats exposed to chronic stress reduced phosphorylation of components of the mTOR signaling pathway was observed (Chandran et al., 2013).

Figure 1 summarizes the autophagy pathway and its components reported to be deviated in neuropsychiatric disorders.

\section{THE POTENTIAL OF AUTOPHAGY-RELATED THERAPEUTIC STRATEGIES FOR THE TREATMENT OF NEURODEGENERATIVE AND PSYCHIATRIC DISORDERS}

As summarized above both neurodegenerative diseases and psychiatric disorders exhibit characteristics of aberrant autophagy which might be a central pathophysiological factor. Therefore, we contend that modifying autophagy pharmacologically might be an approach to prevent or to halt neurodegenerative and psychiatric disorders by potentially enhancing the removal of aggregated mutant proteins/dysfunctional mitochondria by their degradation, thus protecting from cell death/distrees. Evolving conceptualization supported by molecular, cellular and behavioral data suggests that affective disorders might be regarded as neurodegenerative ones involving plasticity- and resilience-related cascades (Bachmann et al., 2005; Einat and Manji, 2006; Racagni and Popoli, 2008; Calabrese et al., 2009). In this respect, one study suggested that protein aggregation is a common feature of neurodegenerative diseases (Taylor et al., 2002) while another one - that beyond neurodegenerative disorders protein aggregation might also be involved in affective disorders (Leliveld et al., 2008). The latter reported an increase in protein aggregates in post-mortem brains of affective disorders (MDD and BPDs) and schizophrenia patients as compared to controls.

The mTOR-dependent autophagy enhancers metformin, resveratrol, isorhynchophylline and rapamycin have all been shown to increase $\alpha$-synucleine clearance and reduce cell death in various PD and AD models (Pan et al., 2009; Wu et al., 2011; Lu et al., 2012; Ng et al., 2012; Kou and Chen, 2017). Mitochondrial pyruvate carrier (MPC) is a key controller of cellular metabolism that influences mTOR activation and has recently been reported to regulate autophagy. A compound that specifically targets MPC, to reduce its activity exhibited neuroprotective and antiinflammatory effects in several PD models (Ghosh et al., 2016).

The mTOR-independent autophagy enhancers include: a. Trehalose, a disaccharide present in many non-mammalian species, induces autophagy and has been shown to enhance the clearance of mutant huntingtin and $\alpha$-synuclein mutants in mammalian cell cultures such as monkey kidney and human neuroblastoma cells (Sarkar et al., 2007a). Studies toward unraveling the mechanism by which trehalose regulates autophagy revealed the involvement of autophago-lysosomal components including TFEB (Settembre and Ballabio, 2011) as well as transient enlargement and permeabilization of the lysosomes. Furthermore, trehalose treatment led to transcriptional activation of autophagy-related TFEB targets (Rusmini et al., 2018). The latter corroborates our group's report that trehalose administration to mice resulted in reduction of frontal cortex p62/beclin1 ratio suggesting enhancement of autophagy (Kara et al., 2013). b. $\mathrm{Ca}^{2+}$ channel antagonists, calpains, cyclic AMP (cAMP) and Gi signaling activators induce autophagy in a variety of cells in an mTOR-independent pathway. For example, reduction of cAMP which regulates $\mathrm{IP}_{3}$ levels lead to a cascade of signaling with numerous potential points where autophagy can be induced (Williams et al., 2008). c. Three small-molecule enhancers (SMER) and inhibitors (SMIR) were identified with the ability to enhance autophagy clearance of mutant huntingtin and A53T $\alpha$-synuclein in yeast independently of rapamycin (Sarkar et al., 2007b). Antidepressants and mood stabilizers have also been reported to affect autophagy. Lithium, the prototype mood stabilizing drug commonly used in the treatment of bipolar patients, affects neurons at an array of parameters including neuronal growth factors, inhibition of oxidative stress and autophagy (Camins et al., 2009), resulting, in animal models, in neuroprotection - potentially beneficial against neurodegeneration (Sasaki et al., 2006; Bian et al., 2007). It has been shown (Williams et al., 2002; Sarkar et al., 2005) and confirmed (Sade et al., 2016) that lithium is an autophagy enhancer via inositol metabolism in several mammalian cell lines and in mouse brain. In this context lithium has also been 


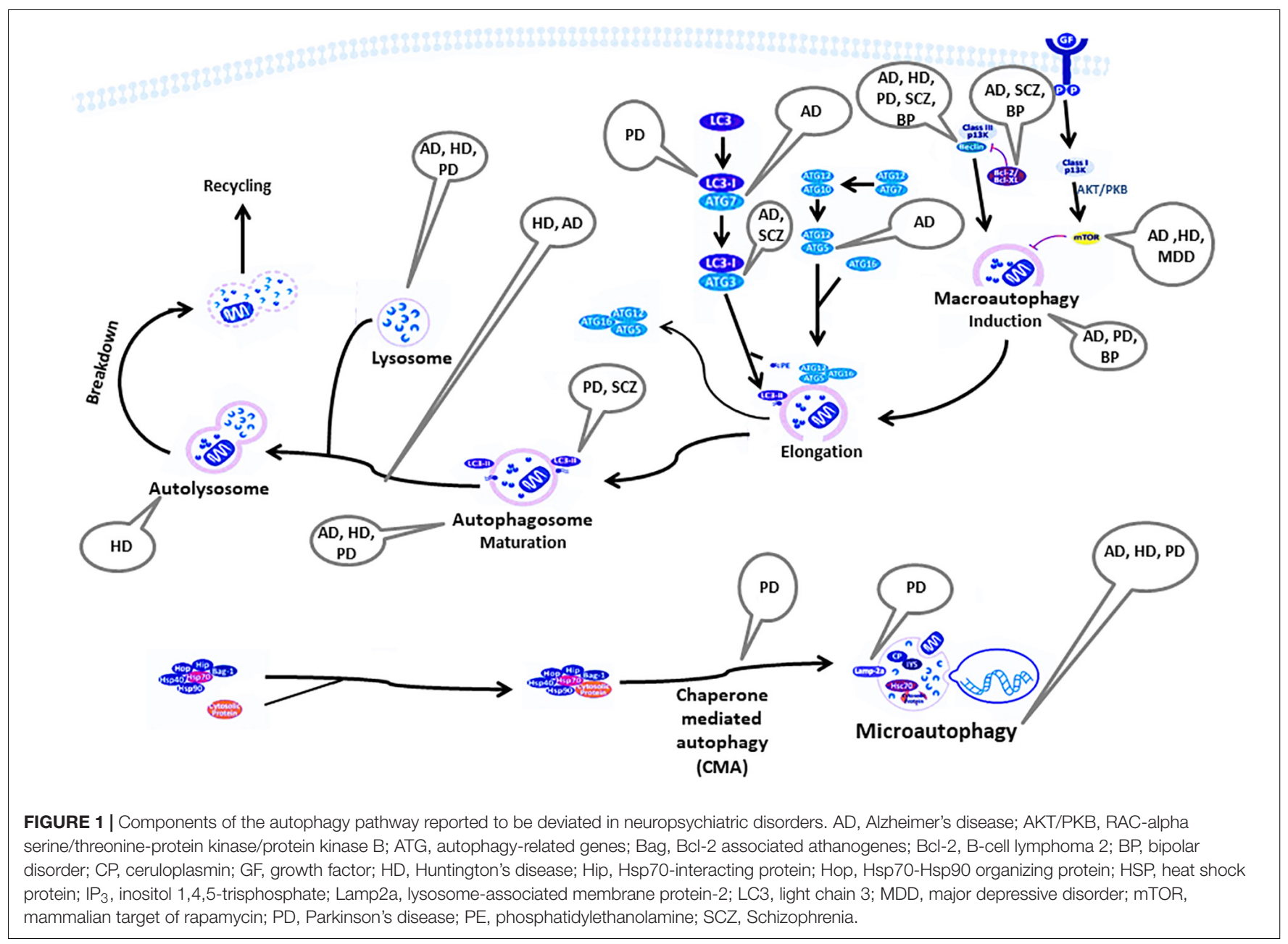

shown to reduce neurodegeneration in Drosophila models of HD (Sarkar et al., 2008). The beneficial effect was shown to be achieved by enhancing autophagic activity through inhibition of inositol monophosphatase and inositol transporters, free inositol depletion and decreasing inositol 1,4,5-trisphosphate $\left(\mathrm{IP}_{3}\right)$ levels (Phiel and Klein, 2001; Sarkar et al., 2005; Sarkar and Rubinsztein, 2006). It resulted in enhanced clearance of autophagy substrates like mutant huntingtin and a-synucleins (Sarkar et al., 2005, 2008). However, opposite responses of autophagy to lithium were also observed. Lithium administration to neonatal rats with hypoxia-ischemia (HI) brain injury inhibited autophagy, as reflected by lowered levels of immuno-stained LC3 accompanied by neuroprotection. In contrast, increased LC3 levels were observed in rats with $\mathrm{HI}$ without lithium treatment (Li Q. et al., 2010). It is unclear whether a direct lithium's neuroprotective effect reduced the requirement for autophagy, or whether lithium directly downregulated autophagy. Attempts to elucidate whether enhanced autophagy following $\mathrm{HI}$ reflects a failed compensatory effect or the mechanism mediating cell death have been limited due to the lack of specificity of pharmacological inhibitors.

Lithium has also been shown to inhibit (in vitro) glycogen synthase kinase-3 $\beta$ (GSK-3 $\beta$ ) that reduces autophagy by activating mTOR (Klein and Melton, 1996; Stambolic et al.,
1996; Sarkar et al., 2008). However, we have recently shown that lithium's inhibition of GSK-3 $\beta$ does not occur in lithiumtreated patients (Azab et al., 2017). Additional mood stabilizers proven to cause inositol depletion (Williams et al., 2002), valproic acid and carbamazepine, were also reported to upregulate autophagy (Fu et al., 2010; Renna et al., 2010), reduce apoptosis and alleviate mitochondrial dysfunction in rotenone-exposed SH-SY5Y cells, a PD model (Williams et al., 2008; Hou et al., 2015).

Ketamine, a recently recognized rapid-acting antidepressant (Berman et al., 2000; Zarate et al., 2006b; Diazgranados et al., 2010), has been shown to activate mTOR in rat prefrontal cortex resulting in increased synaptic signaling proteins and number and function of new spine synapses (Li N. et al., 2010). A similar effect of a continued increase of mTOR phosphorylation from baseline up to $100 \mathrm{~min}$ following ketamine infusion was observed in peripheral blood cells of a depressed patient (Li N. et al., 2010) and in the plasma of three patients (Denk et al., 2011; Yang et al., 2013). Activation of mTOR may be expected to inhibit autophagy rather than activate it. However, except from mTOR's role as an autophagy inhibitor, mTOR is influenced by the activity of neuronal receptors including $N$-methyl-D-aspartate (NMDA) and tyrosine kinase (Trk) B. Indeed, chronic ketamine 
administration had no effect on depressive-like behavior and frontal cortex autophagy in mice (Kara et al., 2017).

Conventional antidepressant drugs have also been shown to enhance autophagy via several molecular mechanisms [Alcocer-Gomez et al., 2017 (Gulbins et al., 2018 \#379)]. Amitriptyline and citalopram upregulated the expression of the autophagy markers LC3B-II and Beclin1 in primary astrocytes and neurons (Zschocke and Rein, 2011). Beclin1 was increased following acute antidepressant treatment in mouse brain (Gassen et al., 2014). In a mouse model of depression, learned helplessness (LH), treatment with fluoxetine resulted in elevation of Beclin1 expression and mitophagy protein levels ( $\mathrm{Li}$ et al., 2016). Exposure of glioma cells to imipramine inhibited $\mathrm{PI} 3 \mathrm{~K} / \mathrm{Akt} / \mathrm{mTOR}$ signaling, stimulated the conversion of LC3-I to LC3-II and re-distributed LC3 to autophagosomes, suggesting stimulation of autophagy progression (Jeon et al., 2011).

An add-on double blind placebo-controlled pilot phase II study of AVN-211 (3-sulfonyl-pyrazolo[1,5-a]pyrimidine), a specific antagonist of the G-protein coupled receptor 5HT6R, showed a pro-cognitive (attention) effect in patients with schizophrenia stabilized on antipsychotic medication (Morozova et al., 2014). 5-HT6R activation increased mTOR signaling in rodent prefrontal cortex (Meffre et al., 2012). Hence, these observations raise the possibility that recruitment of mTOR by prefrontal 5 -HT6R plays a role in the ruffled cognition in schizophrenia and offers a novel target for its therapy.

\section{DISCUSSION}

Autophagy plays a key role in maintaining cellular homeostasis and survival by promoting a clearance mechanism of mutant/misfolded proteins. Despite a dramatic progress in understanding the molecular and cellular mechanisms of autophagy in the past two decades full comprehension is still limited. Reviewed here is evidence of autophagy's important role in neurodegenerative and mental illnesses. However, it is still unclear under which circumstances enhanced autophagy plays a role in cell death or represents a rescue mechanism with protective effects (Rubinsztein et al., 2005; Carloni et al., 2008; Koike et al., 2008). Furthermore, whether autophagy can cause cell death directly or is it a secondary effect of apoptosis remains an open question (Shintani and Klionsky, 2004). Some studies have shown that inhibition of autophagy increases neuronal survival in cases such as hypoxic/ischemic brain injury in mice and necrotic cell death in Caenorhabditis elegans (Yang et al., 2007; Cherra and Chu, 2008; Koike et al., 2008; Samara et al., 2008; Uchiyama et al., 2009). It should be noted though that the increased number of autophagosomes is not always an indicator of enhanced autophagy. It may also be translated as either accumulation of uncleared autophagosomes due to impaired fusion to the lysosomes, or as a dysfunction in one of the various autophagy induction pathways (Boland et al., 2008; Rubinsztein et al., 2009).

Autophagic failure consequences are different depending on the stage at which failure occurs. It might occur at the level of autophagosome formation, resulting in accumulation of discarded cargo such as misfolded proteins and/or dysfunctional mitochondria leading to a toxic cost to the neuron (Hara et al., 2006; Komatsu et al., 2006, 2007). Another failure level might be the recognition of autophagic cargo. This may cause the same corollaries as above, and depends on the extent of the recognition of dysfunction and the type of cargo. A third level of defect might arise if the autophagosomes are not cleared properly, leading to their accumulation. This might interfere with intracellular trafficking and even result in toxic outcomes as seen in AD, where the presence of APP in autophagosomes results in the production of $\beta$-amyloids (Yu et al., 2005). Hence, as summarized by Zhang et al. (2017) both ubiquitin proteasomal system (UPS) dysfunction and the autophagylysosomal pathway (ALP) impairment might be involved in the pathological misfolded/aggregated protein clearance. Identifying the specific level of autophagy failure is imperative for future development of therapeutic modalities.

In relation to potential therapeutic strategies for the treatment of neuropsychiatric disorders based on the intervention in autophagy lithium provides a crossroad linking autophagy, mood stabilization (an anti-depressant and an anti-manic agent) and, possibly, neurodegenerative/neurodevelopmental disorders. Lithium has been shown to enhance autophagy and to upregulate mitochondrial function, both effects mediated by inositol depletion (Sarkar et al., 2005). Enhanced autophagy may result in enhanced clearance of damaged mitochondria (mitophagy) resulting in increased mitochondrial turnover and, consequently, in upregulated mitochondrial function. Indeed, a transcriptomics study of our group found "upregulation of mitochondrial genes in lithium treated mice and in phosphoinositide cycle-related knockout mice" (Toker and Agam, 2014; Toker et al., 2014) corroborating reports regarding mitochondrial dysfunction in bipolar patients (Wang, 2007). Hence, lithium might be considered as a treatment strategy to enhance autophagy in an mTOR-independent manner in neurodegenerative diseases such as HD (Sarkar et al., 2005). Another therapeutic option might have been rapamycin-induced mTOR inhibition. However, since mTOR inhibition affects other pathways (Ravikumar et al., 2006), and since chronic rapamycin treatment is accompanied by severe side effects (Bove et al., 2011), more specific ways to activate autophagy are required. Furthermore, it has been shown that rapamycin loses its efficacy during the progression of HD (Ravikumar et al., 2004). A different potential thinking path may be based on the finding that neuroinflammation affects brain autophagy and contributes to the progression of neurodegenerative disorders (Francois et al., 2014). This may imply a new therapeutic strategy for CNS disorders. An additional issue to be considered is genetic findings showing that proteins related to neurodegeneration, such as huntingtin, participate in autophagy as one of their physiological functions (Menzies et al., 2017). This suggests that the applicability of targeting autophagy as a whole might be limited in neurodegenerative diseases (Scrivo et al., 2018). Hence, perhaps future efforts should focus on targeting specific types and steps of the autophagic process.

When considering intervention in autophagy as an approach to overcome neuropsychiatric disorders age might be a crucial 
factor to be considered. In adulthood-related disorders such as neurodegenerative diseases (and certain tumors) autophagyinducing drugs have been shown to be beneficial (Levine and Kroemer, 2008; Winslow and Rubinsztein, 2008; Rubinsztein et al., 2012). We have previously demonstrated antidepressiveand antimanic-like effect of autophagy enhancers in adult rodents (Kara et al., 2013, 2017; Sade et al., 2016). Perplexingly, as mentioned above, $\mathrm{HI}$ in the immature brain resulted in increased autophagy in injured neurons (Li Q. et al., 2010). In addition the authors demonstrated that lithium protects neurons derived from postnatal day 8-9 of rodents by inhibiting apoptosis and autophagy. In this respect it is interesting to note that a recent clinical trial (Yuan et al., 2018) found that low dose lithium (well established to enhance autophagy in cells in culture and adult brain) improved cognitive performance and adaptive behavior in children aged 4-11 years old with intellectual disability. As information regarding autophagy in oligodendrocytes in intellectual disability is still missing, it is imperative, both at the basic/translational and at the applicative level, to investigate whether there are age-related differences in the mechanism(s) of lithium-induced beneficial outcomes via the drug's effect on autophagy.

\section{REFERENCES}

Abeliovich, A., Schmitz, Y., Farinas, I., Choi-Lundberg, D., Ho, W. H., Castillo, P. E., et al. (2000). Mice lacking alpha-synuclein display functional deficits in the nigrostriatal dopamine system. Neuron 25, 239-252. doi: 10.1016/s08966273(00)80886-7

Alcocer-Gomez, E., Casas-Barquero, N., Williams, M. R., Romero-Guillena, S. L., Canadas-Lozano, D., Bullon, P., et al. (2017). Antidepressants induce autophagy dependent-NLRP3-inflammasome inhibition in Major depressive disorder. Pharmacol. Res. 121, 114-121. doi: 10.1016/j.phrs.2017. 04.028

Alzheimer's, A. (2016). 2016 Alzheimer's disease facts and figures. Alzheimers Dement. 12, 459-509. doi: 10.1016/j.jalz.2016.03.001

American Psychiatric Association (2016). DSM-5 Classification. Arlington, VA: American Psychiatric Association.

Anglade, P., Vyas, S., Javoy-Agid, F., Herrero, M. T., Michel, P. P., Marquez, J., et al. (1997). Apoptosis and autophagy in nigral neurons of patients with Parkinson's disease. Histol. Histopathol. 12, 25-31.

Ashkenazi, A., Bento, C. F., Ricketts, T., Vicinanza, M., Siddiqi, F., Pavel, M., et al. (2017). Polyglutamine tracts regulate beclin 1-dependent autophagy. Nature 545, 108-111. doi: 10.1038/nature22078

Azab, A. N., Vainer, E., Agam, G., and Bersudsky, Y. (2017). Lymphocyte Phospho-Ser-9-GSK-3beta/Total GSK-3beta protein levels ratio is not affected by chronic lithium or valproate treatment in euthymic patients with bipolar disorder. J. Clin. Psychopharmacol. 37, 226-230. doi: 10.1097/JCP.000000000 0000654

Bachmann, R. F., Schloesser, R. J., Gould, T. D., and Manji, H. K. (2005). Mood stabilizers target cellular plasticity and resilience cascades: implications for the development of novel therapeutics. Mol. Neurobiol. 32, 173-202. doi: 10.1385/ $\mathrm{mn} \% 3 \mathrm{~A} 32 \% 3 \mathrm{~A} 2 \% 3 \mathrm{~A} 173$

Balu, D. T., and Coyle, J. T. (2011). Neuroplasticity signaling pathways linked to the pathophysiology of schizophrenia. Neurosci. Biobehav. Rev. 35, 848-870. doi: 10.1016/j.neubiorev.2010.10.005

Bassan, M., Zamostiano, R., Davidson, A., Pinhasov, A., Giladi, E., Perl, O., et al. (1999). Complete sequence of a novel protein containing a femtomolar-activitydependent neuroprotective peptide. J. Neurochem. 72, 1283-1293. doi: 10.1046/ j.1471-4159.1999.0721283.x
In conclusion, stimulation of autophagy in neuropsychiatric disorders may be a neuroprotective strategy, keeping in mind avoiding excessive process which might be destructive. It is essential to take into account that modifying autophagy may lead to diverse consequences and interfere with mechanisms yet unraveled. By revealing the molecular mechanisms involved in autophagy and the role of this process in neuronal life and death pathways it might be possible to either inhibit or stimulate autophagy for therapeutic purposes.

\section{AUTHOR CONTRIBUTIONS}

OD and TB-Y ran the literature search and prepared the first draft. GA instructed OD and TB-Y, and brought the manuscript for submission.

\section{FUNDING}

This work was supported by Israel Science Foundation research grant to GA and an Eshkol scholarship, Ministry of Science and Technology to OD.

Beilina, A., and Cookson, M. R. (2016). Genes associated with Parkinson's disease: regulation of autophagy and beyond. J. Neurochem. 139(Suppl. 1), 91-107. doi: $10.1111 /$ jnc. 13266

Belmaker, R. H. (2004). Bipolar disorder. N. Engl. J. Med. 351, 476-486. doi: 10.1056/NEJMra035354

Belmaker, R. H., and Agam, G. (2008). Major depressive disorder. N. Engl. J. Med. 358, 55-68. doi: 10.1056/NEJMra073096

Beneto, C. F., Ashkenazi, A., Jimenez-Sanchez, M., and Rubinsztein, D. C. (2016). The Parkinson's disease-associated genes ATP13A2 and SYT11 regulate autophagy via a common pathway. Nat. Commun. 7:11803. doi: 10.1038/ ncomms 11803

Berman, R. M., Cappiello, A., Anand, A., Oren, D. A., Heninger, G. R., Charney, D. S., et al. (2000). Antidepressant effects of ketamine in depressed patients. Biol. Psychiatry 47, 351-354. doi: 10.1016/s0006-3223(99)00230-9

Bian, Q., Shi, T., Chuang, D. M., and Qian, Y. (2007). Lithium reduces ischemiainduced hippocampal CA1 damage and behavioral deficits in gerbils. Brain Res. 1184, 270-276. doi: 10.1016/j.brainres.2007.09.054

Boland, B., Kumar, A., Lee, S., Platt, F. M., Wegiel, J., Yu, W. H., et al. (2008). Autophagy induction and autophagosome clearance in neurons: relationship to autophagic pathology in Alzheimer's disease. J. Neurosci. 28, 6926-6937. doi: 10.1523/JNEUROSCI.0800-08.2008

Bove, J., Martinez-Vicente, M., and Vila, M. (2011). Fighting neurodegeneration with rapamycin: mechanistic insights. Nat. Rev. Neurosci. 12, 437-452. doi: $10.1038 / \mathrm{nrn} 3068$

Calabrese, F., Molteni, R., Racagni, G., and Riva, M. A. (2009). Neuronal plasticity: a link between stress and mood disorders. Psychoneuroendocrinology 34(Suppl. 1), S208-S216. doi: 10.1016/j.psyneuen.2009.05.014

Camins, A., Verdaguer, E., Junyent, F., Yeste-Velasco, M., Pelegri, C., Vilaplana, J., et al. (2009). Potential mechanisms involved in the prevention of neurodegenerative diseases by lithium. CNS Neurosci. Ther. 15, 333-344. doi: 10.1111/j.1755-5949.2009.00086.x

Cao, Y., and Klionsky, D. J. (2007). Physiological functions of Atg6/Beclin 1: a unique autophagy-related protein. Cell Res. 17, 839-849. doi: $10.1038 / \mathrm{cr} .2007 .78$

Carloni, S., Buonocore, G., and Balduini, W. (2008). Protective role of autophagy in neonatal hypoxia-ischemia induced brain injury. Neurobiol. Dis. 32, 329-339. doi: 10.1016/j.nbd.2008.07.022 
Chandran, A., Iyo, A. H., Jernigan, C. S., Legutko, B., Austin, M. C., and Karolewicz, B. (2013). Reduced phosphorylation of the mTOR signaling pathway components in the amygdala of rats exposed to chronic stress. Prog. Neuropsychopharmacol. Biol. Psychiatry 40, 240-245. doi: 10.1016/j.pnpbp. 2012.08.001

Cheong, H., and Klionsky, D. J. (2014). Dual role of Atg1 in regulation of autophagy-specific PAS assembly in Saccharomyces cerevisiae. Autophagy 4, 724-726. doi: 10.4161/auto.6375

Cherra, S. J. III, and Chu, C. T. (2008). Autophagy in neuroprotection and neurodegeneration: a question of balance. Future Neurol. 3, 309-323. doi: 10. 2217/14796708.3.3.309

Clarke, P. G. (1990). Developmental cell death: morphological diversity and multiple mechanisms. Anat. Embryol. 181, 195-213.

Cleary, C., Linde, J. A., Hiscock, K. M., Hadas, I., Belmaker, R. H., Agam, G., et al. (2008). Antidepressive-like effects of rapamycin in animal models: implications for mTOR inhibition as a new target for treatment of affective disorders. Brain Res. Bull. 76, 469-473. doi: 10.1016/j.brainresbull.2008. 03.005

Cuervo, A. M., Stefanis, L., Fredenburg, R., Lansbury, P. T., and Sulzer, D. (2004). Impaired degradation of mutant alpha-synuclein by chaperone-mediated autophagy. Science 305, 1292-1295. doi: 10.1126/science.1101738

Denk, M. C., Rewerts, C., Holsboer, F., Erhardt-Lehmann, A., and Turck, C. W. (2011). Monitoring ketamine treatment response in a depressed patient via peripheral mammalian target of rapamycin activation. Am. J. Psychiatry 168, 751-752. doi: 10.1176/appi.ajp.2011.11010128

Diazgranados, N., Ibrahim, L., Brutsche, N. E., Newberg, A., Kronstein, P., Khalife, S., et al. (2010). A randomized add-on trial of an N-methyl-D-aspartate antagonist in treatment-resistant bipolar depression. Arch. Gen. Psychiatry 67, 793-802. doi: 10.1001/archgenpsychiatry.2010.90

Ding, H., Huang, Z., Chen, M., Wang, C., Chen, X., Chen, J., et al. (2016). Identification of a panel of five serum miRNAs as a biomarker for Parkinson's disease. Parkinsonism Relat. Disord. 22, 68-73. doi: 10.1016/j.parkreldis.2015. 11.014

Dohi, E., Tanaka, S., Seki, T., Miyagi, T., Hide, I., Takahashi, T., et al. (2012). Hypoxic stress activates chaperone-mediated autophagy and modulates neuronal cell survival. Neurochem. Int. 60, 431-442. doi: 10.1016/j.neuint.2012. 01.020

Dresner, E., Agam, G., and Gozes, I. (2011). Activity-dependent neuroprotective protein (ADNP) expression level is correlated with the expression of the sister protein ADNP2: deregulation in schizophrenia. Eur. Neuropsychopharmacol. 21, 355-361. doi: 10.1016/j.euroneuro.2010.06.004

Duda, J. E., Giasson, B. I., Mabon, M. E., Lee, V. M., and Trojanowski, J. Q. (2002). Novel antibodies to synuclein show abundant striatal pathology in Lewy body diseases. Ann. Neurol. 52, 205-210. doi: 10.1002/ana.10279

Einat, H., and Manji, H. K. (2006). Cellular plasticity cascades: genes-to-behavior pathways in animal models of bipolar disorder. Biol. Psychiatry 59, 1160-1171. doi: 10.1016/j.biopsych.2005.11.004

Eisenberg-Lerner, A., Bialik, S., Simon, H. U., and Kimchi, A. (2009). Life and death partners: apoptosis, autophagy and the cross-talk between them. Cell Death Differ. 16, 966-975. doi: 10.1038/cdd.2009.33

Eshel, N., and Roiser, J. P. (2010). Reward and punishment processing in depression. Biol. Psychiatry 68, 118-124. doi: 10.1016/j.biopsych.2010.01.027

Farre, J. C., Krick, R., Subramani, S., and Thumm, M. (2009). Turnover of organelles by autophagy in yeast. Curr. Opin. Cell Biol. 21, 522-530. doi: 10. 1016/j.ceb.2009.04.015

Farre, J. C., and Subramani, S. (2004). Peroxisome turnover by micropexophagy: an autophagy-related process. Trends Cell Biol. 14, 515-523. doi: 10.1016/j.tcb. 2004.07.014

Fimia, G. M., Stoykova, A., Romagnoli, A., Giunta, L., Di Bartolomeo, S., Nardacci, R., et al. (2007). Ambral regulates autophagy and development of the nervous system. Nature 447, 1121-1125. doi: 10.1038/nature05925

Francois, A., Terro, F., Quellard, N., Fernandez, B., Chassaing, D., Janet, T., et al. (2014). Impairment of autophagy in the central nervous system during lipopolysaccharide-induced inflammatory stress in mice. Mol. Brain 7:56. doi: 10.1186/s13041-014-0056-z

Fu, J., Shao, C. J., Chen, F. R., Ng, H. K., and Chen, Z. P. (2010). Autophagy induced by valproic acid is associated with oxidative stress in glioma cell lines. Neuro Oncol. 12, 328-340. doi: 10.1093/neuonc/nop005
Gassen, N. C., Hartmann, J., Schmidt, M. V., and Rein, T. (2015). FKBP5/FKBP51 enhances autophagy to synergize with antidepressant action. Autophagy 11, 578-580. doi: 10.1080/15548627.2015.1017224

Gassen, N. C., Hartmann, J., Zschocke, J., Stepan, J., Hafner, K., Zellner, A., et al. (2014). Association of FKBP51 with priming of autophagy pathways and mediation of antidepressant treatment response: evidence in cells, mice, and humans. PLoS Med. 11:e1001755. doi: 10.1371/journal.pmed.1001755

Gelb, D. J., Oliver, E., and Gilman, S. (1999). Diagnostic criteria for Parkinson disease. Arch. Neurol. 56, 33-39.

Ghosh, A., Tyson, T., George, S., Hildebrandt, E. N., Steiner, J. A., Madaj, Z., et al. (2016). Mitochondrial pyruvate carrier regulates autophagy, inflammation, and neurodegeneration in experimental models of Parkinson's disease. Sci. Transl. Med. 8:368ra174. doi: 10.1126/scitranslmed.aag2210

Gil, J. M., and Rego, A. C. (2008). Mechanisms of neurodegeneration in Huntington's disease. Eur. J. Neurosci. 27, 2803-2820. doi: 10.1111/j.1460-9568. 2008.06310.x

Ginet, V., Puyal, J., Clarke, P. G., and Truttmann, A. C. (2009). Enhancement of autophagic flux after neonatal cerebral hypoxia-ischemia and its regionspecific relationship to apoptotic mechanisms. Am. J. Pathol. 175, 1962-1974. doi: 10.2353/ajpath.2009.090463

Goldstein, L. S. B., and Yang, Z. H. (2000). Microtubule-based transport systems in neurons: the roles of kinesins and dyneins. Ann. Rev. Neurosci. 23, 39-71. doi: 10.1146/annurev.neuro.23.1.39

Goodwin, F. K., and Jamison, K. R. (1990). Manic-Depressive Illness. New York, NY: Oxford University Press.

Gould, T. D., Quiroz, J. A., Singh, J., Zarate, C. A., and Manji, H. K. (2004). Emerging experimental therapeutics for bipolar disorder: insights from the molecular and cellular actions of current mood stabilizers. Mol. Psychiatry 9, 734-755. doi: 10.1038/sj.mp.4001518

Gozes, I., and Divinski, I. (2007). NAP, a neuroprotective drug candidate in clinical trials, stimulates microtubule assembly in the living cell. Curr. Alzheimer Res. 4, 507-509. doi: 10.2174/156720507783018208

Gozuacik, D., and Kimchi, A. (2004). Autophagy as a cell death and tumor suppressor mechanism. Oncogene 23, 2891-2906. doi: 10.1038/sj.onc.1207521

Guertin, D. A., and Sabatini, D. M. (2009). The pharmacology of mTOR inhibition. Sci. Signal. 2:pe24. doi: 10.1126/scisignal.267pe24

Gulbins, A., Schumacher, F., Becker, K. A., Wilker, B., Soddemann, M., Boldrin, F., et al. (2018). Antidepressants act by inducing autophagy controlled by sphingomyelin-ceramide. 23, 2324-2346. doi: 10.1038/s41380-018-0090-9

Hara, T., Nakamura, K., Matsui, M., Yamamoto, A., Nakahara, Y., SuzukiMigishima, R., et al. (2006). Suppression of basal autophagy in neural cells causes neurodegenerative disease in mice. Nature 441, 885-889. doi: 10.1038/ nature 04724

He, C., and Levine, B. (2010). The beclin 1 interactome. Curr. Opin. Cell Biol. 22, 140-149. doi: 10.1016/j.ceb.2010.01.001

Horesh, Y., Katsel, P., Haroutunian, V., and Domany, E. (2011). Gene expression signature is shared by patients with Alzheimer's disease and schizophrenia at the superior temporal gyrus. Eur. J. Neurol. 18, 410-424. doi: 10.1111/j.14681331.2010.03166.x

Hou, L., Xiong, N., Liu, L., Huang, J., Han, C., Zhang, G., et al. (2015). Lithium protects dopaminergic cells from rotenone toxicity via autophagy enhancement. BMC Neurosci. 16:82. doi: 10.1186/s12868-015-0222-y

Hu, Z., Yang, B., Mo, X., and Xiao, H. (2015). Mechanism and regulation of autophagy and its role in neuronal diseases. Mol. Neurobiol. 52, 1190-1209. doi: 10.1007/s12035-014-8921-4

Iwata, A., Riley, B. E., Johnston, J. A., and Kopito, R. R. (2005). HDAC6 and microtubules are required for autophagic degradation of aggregated huntingtin. J. Biol. Chem. 280, 40282-40292. doi: 10.1074/jbc.M508786200

Jahreiss, L., Menzies, F. M., and Rubinsztein, D. C. (2008). The itinerary of autophagosomes: from peripheral formation to kiss-and-run fusion with lysosomes. Traffic 9, 574-587. doi: 10.1111/j.1600-0854.2008. 00701.x

Javitt, D. C., Zukin, S. R., Heresco-Levy, U., and Umbricht, D. (2012). Has an angel shown the way? Etiological and therapeutic implications of the PCP/NMDA model of schizophrenia. Schizophr. Bull. 38, 958-966. doi: 10.1093/schbul/ sbs069

Jeon, S. H., Kim, S. H., Kim, Y., Kim, Y. S., Lim, Y., Lee, Y. H., et al. (2011). The tricyclic antidepressant imipramine induces autophagic cell death in U-87MG 
glioma cells. Biochem. Biophys. Res. Commun. 413, 311-317. doi: 10.1016/j.bbrc. 2011.08.093

Jernigan, C. S., Goswami, D. B., Austin, M. C., Iyo, A. H., Chandran, A., Stockmeier, C. A., et al. (2011). The mTOR signaling pathway in the prefrontal cortex is compromised in major depressive disorder. Prog. Neuropsychopharmacol. Biol. Psychiatry 35, 1774-1779. doi: 10.1016/j.pnpbp.2011.05.010

Jevtic, G., Nikolic, T., Mircic, A., Stojkovic, T., Velimirovic, M., Trajkovic, V., et al. (2016). Mitochondrial impairment, apoptosis and autophagy in a rat brain as immediate and long-term effects of perinatal phencyclidine treatment - influence of restraint stress. Prog. Neuropsychopharmacol. Biol. Psychiatry 66, 87-96. doi: 10.1016/j.pnpbp.2015.11.014

Jia, J., and Le, W. (2015). Molecular network of neuronal autophagy in the pathophysiology and treatment of depression. Neurosci. Bull. 31, 427-434. doi: 10.1007/s12264-015-1548-2

Kabeya, Y., Mizushima, N., Ueno, T., Yamamoto, A., Kirisako, T., Noda, T., et al. (2000). LC3, a mammalian homologue of yeast Apg8p, is localized in autophagosome membranes after processing. EMBO J. 19, 5720-5728. doi: 10.1093/emboj/19.21.5720

Kara, N. Z., Agam, G., Anderson, G. W., Zitron, N., and Einat, H. (2017). Lack of effect of chronic ketamine administration on depression-like behavior and frontal cortex autophagy in female and male ICR mice. Behav. Brain Res. 317, 576-580. doi: 10.1016/j.bbr.2016.09.056

Kara, N. Z., Toker, L., Agam, G., Anderson, G. W., Belmaker, R. H., and Einat, H. (2013). Trehalose induced antidepressant-like effects and autophagy enhancement in mice. Psychopharmacology 229, 367-375. doi: 10.1007/s00213013-3119-4

Karabiyik, C., Lee, M. J., and Rubinsztein, D. C. (2017). Autophagy impairment in Parkinson's disease. Essays Biochem. 61, 711-720. doi: 10.1042/EBC20170023

Kegel, K. B., Kim, M., Sapp, E., McIntyre, C., Castano, J. G., Aronin, N., et al. (2000). Huntingtin expression stimulates endosomal-lysosomal activity, endosome tubulation, and autophagy. J. Neurosci. 20, 7268-7278. doi: 10.1523/jneurosci. 20-19-07268.2000

Keller, J. N., Hanni, K. B., and Markesbery, W. R. (2000). Impaired proteasome function in Alzheimer's disease. J. Neurochem. 75, 436-439. doi: 10.1046/j. 1471-4159.2000.0750436.x

Kiel, J. A. (2010). Autophagy in unicellular eukaryotes. Philos. Trans. R. Soc. Lond. B Biol. Sci. 365, 819-830. doi: 10.1098/rstb.2009.0237

Kieseppa, T., Partonen, T., Haukka, J., Kaprio, J., and Lonnqvist, J. (2004). High concordance of bipolar I disorder in a nationwide sample of twins. Am. J. Psychiatry 161, 1814-1821. doi: 10.1176/ajp.161.10.1814

Kirkin, V., McEwan, D. G., Novak, I., and Dikic, I. (2009). A role for ubiquitin in selective autophagy. Mol. Cell 34, 259-269. doi: 10.1016/j.molcel.2009.04.026

Klein, P. S., and Melton, D. A. (1996). A molecular mechanism for the effect of lithium on development. Proc. Natl. Acad. Sci. U.S.A. 93, 8455-8459. doi: 10.1073/pnas.93.16.8455

Koike, M., Shibata, M., Tadakoshi, M., Gotoh, K., Komatsu, M., Waguri, S., et al. (2008). Inhibition of autophagy prevents hippocampal pyramidal neuron death after hypoxic-ischemic injury. Am. J. Pathol. 172, 454-469. doi: 10.2353/ajpath. 2008.070876

Komatsu, M., Waguri, S., Chiba, T., Murata, S., Iwata, J., Tanida, I., et al. (2006). Loss of autophagy in the central nervous system causes neurodegeneration in mice. Nature 441, 880-884. doi: 10.1038/nature04723

Komatsu, M., Wang, Q. J., Holstein, G. R., Friedrich, V. L. Jr., Iwata, J., Kominami, E., et al. (2007). Essential role for autophagy protein Atg7 in the maintenance of axonal homeostasis and the prevention of axonal degeneration. Proc. Natl. Acad. Sci. U.S.A. 104, 14489-14494. doi: 10.1073/pnas.070 1311104

Kou, X., and Chen, N. (2017). Resveratrol as a natural autophagy regulator for prevention and treatment of Alzheimer's disease. Nutrients 9:E927. doi: 10. 3390/nu9090927

Kroemer, G., and Levine, B. (2008). Autophagic cell death: the story of a misnomer. Nat. Rev. Mol. Cell Biol. 9, 1004-1010. doi: 10.1038/nrm2529

Kuhn, M., Hoger, N., Feige, B., Blechert, J., Normann, C., and Nissen, C. (2014). Fear extinction as a model for synaptic plasticity in major depressive disorder. PLoS One 9:e115280. doi: 10.1371/journal.pone.0115280

Larsen, M. H., Mikkelsen, J. D., Hay-Schmidt, A., and Sandi, C. (2010). Regulation of brain-derived neurotrophic factor (BDNF) in the chronic unpredictable stress rat model and the effects of chronic antidepressant treatment. J. Psychiatr. Res. 44, 808-816. doi: 10.1016/j.jpsychires.2010.01.005

Lee, J. H., Yu, W. H., Kumar, A., Lee, S., Mohan, P. S., Peterhoff, C. M., et al. (2010). Lysosomal proteolysis and autophagy require presenilin 1 and are disrupted by Alzheimer-related PS1 mutations. Cell 141, 1146-1158. doi: 10.1016/j.cell.2010. 05.008

Leker, R. R., Teichner, A., Grigoriadis, N., Ovadia, H., Brenneman, D. E., Fridkin, M., et al. (2002). NAP, a femtomolar-acting peptide, protects the brain against ischemic injury by reducing apoptotic death. Stroke 33, 1085-1092. doi: 10 . 1161/01.str.0000014207.05597.d7

Leliveld, S. R., Bader, V., Hendriks, P., Prikulis, I., Sajnani, G., Requena, J. R., et al. (2008). Insolubility of disrupted-in-schizophrenia 1 disrupts oligomerdependent interactions with nuclear distribution element 1 and is associated with sporadic mental disease. J. Neurosci. 28, 3839-3845. doi: 10.1523/ JNEUROSCI.5389-07.2008

Levine, B., and Klionsky, D. J. (2004). Development by self-digestion: molecular mechanisms and biological functions of autophagy. Dev. Cell 6, 463-477.

Levine, B., and Kroemer, G. (2008). Autophagy in the pathogenesis of disease. Cell 132, 27-42. doi: 10.1016/j.cell.2007.12.018

Li, D., Zheng, J., Wang, M., Feng, L., Ren, Z., Liu, Y., et al. (2016). Changes of TSPO-mediated mitophagy signaling pathway in learned helplessness mice. Psychiatry Res. 245, 141-147. doi: 10.1016/j.psychres.2016.02.068

Li, N., Lee, B., Liu, R. J., Banasr, M., Dwyer, J. M., Iwata, M., et al. (2010). mTOR-dependent synapse formation underlies the rapid antidepressant effects of NMDA antagonists. Science 329, 959-964. doi: 10.1126/science.1190287

Li, Q., Li, H., Roughton, K., Wang, X., Kroemer, G., Blomgren, K., et al. (2010). Lithium reduces apoptosis and autophagy after neonatal hypoxia-ischemia. Cell Death Dis. 1:e56. doi: 10.1038/cddis.2010.33

Li, Q., Liu, Y., and Sun, M. (2017). Autophagy and Alzheimer's disease. Cell. Mol. Neurobiol. 37, 377-388. doi: 10.1007/s10571-016-0386-8

Lieberman, J. A. (1999). Is schizophrenia a neurodegenerative disorder? A clinical and neurobiological perspective. Biol. Psychiatry 46, 729-739. doi: 10.1016/ s0006-3223(99)00147-x

Lim, J., Kim, H. W., Youdim, M. B., Rhyu, I. J., Choe, K. M., and Oh, Y. J. (2011). Binding preference of p62 towards LC3-1l during dopaminergic neurotoxininduced impairment of autophagic flux. Autophagy 7, 51-60. doi: 10.4161/auto. 7.1.13909

Liu, X., Hou, D., Lin, F., Luo, J., Xie, J., Wang, Y., et al. (2018). The role of neurovascular unit damage in the occurrence and development of Alzheimer's disease. Rev. Neurosci.

Liu, Y., Song, Y., and Zhu, X. (2017). MicroRNA-181a regulates apoptosis and autophagy process in Parkinson's disease by inhibiting p38 mitogen-activated protein kinase (MAPK)/c-Jun N-terminal kinases (JNK) signaling pathways. Med. Sci. Monit. 23, 1597-1606. doi: 10.12659/msm.900218

Lu, J. H., Tan, J. Q., Durairajan, S. S., Liu, L. F., Zhang, Z. H., Ma, L., et al. (2012). Isorhynchophylline, a natural alkaloid, promotes the degradation of alpha-synuclein in neuronal cells via inducing autophagy. Autophagy 8, 98-108. doi: 10.4161/auto.8.1.18313

Manji, H. K., and Lenox, R. H. (1998). Lithium: a molecular transducer of moodstabilization in the treatment of bipolar disorder. Neuropsychopharmacology 19, 161-166. doi: 10.1016/S0893-133X(98)00021-9

Markossian, K. A., and Kurganov, B. I. (2004). Protein folding, misfolding, and aggregation. Formation of inclusion bodies and aggresomes. Biochemistry 69, 971-984. doi: 10.1023/b\%3Abiry.0000043539.07961.4c

Martin, J. B., and Gusella, J. F. (1986). Huntington's disease. Pathogenesis and management. N. Engl. J. Med. 315, 1267-1276. doi: 10.1056/ NEJM198611133152006

Martinet, W., Agostinis, P., Vanhoecke, B., Dewaele, M., and De Meyer, G. R. (2009). Autophagy in disease: a double-edged sword with therapeutic potential. Clin. Sci. 116, 697-712. doi: 10.1042/CS20080508

Martinez-Vicente, M., and Cuervo, A. M. (2007). Autophagy and neurodegeneration: when the cleaning crew goes on strike. Lancet Neurol. 6 , 352-361. doi: 10.1016/s1474-4422(07)70076-5

Martinez-Vicente, M., Talloczy, Z., Wong, E., Tang, G. M., Koga, H., Kaushik, S., et al. (2010). Cargo recognition failure is responsible for inefficient autophagy in Huntington's disease. Nat. Neurosci. 13, 567-576. doi: 10.1038/ nn. 2528 
Mazure, N. M., and Pouyssegur, J. (2010). Hypoxia-induced autophagy: cell death or cell survival? Curr. Opin. Cell Biol. 22, 177-180. doi: 10.1016/j.ceb.2009.11.015

McGuffin, P., Rijsdijk, F., Andrew, M., Sham, P., Katz, R., and Cardno, A. (2003). The heritability of bipolar affective disorder and the genetic relationship to unipolar depression. Arch. Gen. Psychiatry 60, 497-502. doi: 10.1001/archpsyc. 60.5.497

Meffre, J., Chaumont-Dubel, S., Mannoury la Cour, C., Loiseau, F., Watson, D. J., Dekeyne, A., et al. (2012). 5-HT(6) receptor recruitment of mTOR as a mechanism for perturbed cognition in schizophrenia. EMBO Mol. Med. 4, 1043-1056. doi: 10.1002/emmm.201201410

Meijer, A. J., and Codogno, P. (2006). Signalling and autophagy regulation in health, aging and disease. Mol. Aspects Med. 27, 411-425. doi: 10.1016/j.mam. 2006.08.002

Menzies, F. M., Fleming, A., Caricasole, A., Bento, C. F., Andrews, S. P., Ashkenazi, A., et al. (2017). Autophagy and neurodegeneration: pathogenic mechanisms and therapeutic opportunities. Neuron 93, 1015-1034. doi: 10.1016/j.neuron. 2017.01.022

Merenlender-Wagner, A., Malishkevich, A., Shemer, Z., Udawela, M., Gibbons, A., Scarr, E., et al. (2015). Autophagy has a key role in the pathophysiology of schizophrenia. Mol. Psychiatry 20, 126-132. doi: 10.1038/mp 2013.174

Merenlender-Wagner, A., Pikman, R., Giladi, E., Andrieux, A., and Gozes, I. (2010). NAP (davunetide) enhances cognitive behavior in the STOP heterozygous mouse-a microtubule-deficient model of schizophrenia. Peptides 31, 1368-1373. doi: 10.1016/j.peptides.2010.04.011

Merenlender-Wagner, A., Shemer, Z., Touloumi, O., Lagoudaki, R., Giladi, E., Andrieux, A., et al. (2014). New horizons in schizophrenia treatment: autophagy protection is coupled with behavioral improvements in a mouse model of schizophrenia. Autophagy 10, 2324-2332. doi: 10.4161/15548627. 2014.984274

Miguel-Hidalgo, J. J., Whittom, A., Villarreal, A., Soni, M., Meshram, A., Pickett, J. C., et al. (2014). Apoptosis-related proteins and proliferation markers in the orbitofrontal cortex in major depressive disorder. J. Affect. Disord. 158, 62-70. doi: 10.1016/j.jad.2014.02.010

Mimmack, M. L., Ryan, M., Baba, H., Navarro-Ruiz, J., Iritani, S., Faull, R. L., et al. (2002). Gene expression analysis in schizophrenia: reproducible upregulation of several members of the apolipoprotein $\mathrm{L}$ family located in a high-susceptibility locus for schizophrenia on chromosome 22. Proc. Natl. Acad. Sci. U.S.A. 99, 4680-4685. doi: 10.1073/pnas.032069099

Mizushima, N. (2007). Autophagy: process and function. Genes Dev. 21, 2861-2873. doi: 10.1101/gad.1599207

Mizushima, N., Levine, B., Cuervo, A. M., and Klionsky, D. J. (2008). Autophagy fights disease through cellular self-digestion. Nature 451, 1069-1075. doi: 10. 1038/nature06639

Moloudizargari, M., Asghari, M. H., Ghobadi, E., Fallah, M., Rasouli, S., and Abdollahi, M. (2017). Autophagy, its mechanisms and regulation: implications in neurodegenerative diseases. Ageing Res. Rev. 40, 64-74. doi: 10.1016/j.arr. 2017.09.005

Morozova, M. A., Lepilkina, T. A., Rupchev, G. E., Beniashvily, A. G., Burminskiy, D. S., Potanin, S. S., et al. (2014). Add-on clinical effects of selective antagonist of 5HT6 receptors AVN-211 (CD-008-0173) in patients with schizophrenia stabilized on antipsychotic treatment: pilot study. CNS Spectr. 19, 316-323. doi: $10.1017 /$ S1092852913000394

Nagata, E., Sawa, A., Ross, C. A., and Snyder, S. H. (2004). Autophagosomelike vacuole formation in Huntington's disease lymphoblasts. Neuroreport 15 , 1325-1328. doi: 10.1097/01.wnr.0000127073.66692.8f

Narendra, D., Tanaka, A., Suen, D. F., and Youle, R. J. (2008). Parkin is recruited selectively to impaired mitochondria and promotes their autophagy. J. Cell Biol. 183, 795-803. doi: $10.1083 /$ jcb.200809125

Ng, C. H., Guan, M. S., Koh, C., Ouyang, X., Yu, F., Tan, E. K., et al. (2012). AMP kinase activation mitigates dopaminergic dysfunction and mitochondrial abnormalities in Drosophila models of Parkinson's disease. J. Neurosci. 32, 14311-14317. doi: 10.1523/JNEUROSCI.0499-12.2012

Nikoletopoulou, V., Markaki, M., Palikaras, K., and Tavernarakis, N. (2013). Crosstalk between apoptosis, necrosis and autophagy. Biochim. Biophys. Acta 1833, 3448-3459. doi: 10.1016/j.bbamcr.2013.06.001
Nishino, I., Fu, J., Tanji, K., Yamada, T., Shimojo, S., Koori, T., et al. (2000). Primary LAMP-2 deficiency causes X-linked vacuolar cardiomyopathy and myopathy (Danon disease). Nature 406, 906-910. doi: 10.1038/35022604

Nixon, R. A. (2007). Autophagy, amyloidogenesis and Alzheimer disease. J. Cell Sci. 120(Pt 23), 4081-4091. doi: 10.1242/jcs.019265

Nixon, R. A., Wegiel, J., Kumar, A., Yu, W. H., Peterhoff, C., Cataldo, A., et al. (2005). Extensive involvement of autophagy in Alzheimer disease: an immunoelectron microscopy study. J. Neuropathol. Exp. Neurol. 64, 113-122. doi: 10.1093/jnen/64.2.113

O'Shea, K. S., and McInnis, M. G. (2015). Induced pluripotent stem cell (iPSC) models of bipolar disorder. Neuropsychopharmacology 40, 248-249. doi: 10. 1038/npp.2014.221

Pan, T., Rawal, P., Wu, Y., Xie, W., Jankovic, J., and Le, W. (2009). Rapamycin protects against rotenone-induced apoptosis through autophagy induction. Neuroscience 164, 541-551. doi: 10.1016/j.neuroscience.2009.08.014

Perala, J., Suvisaari, J., Saarni, S. I., Kuoppasalmi, K., Isometsa, E., Pirkola, S., et al. (2007). Lifetime prevalence of psychotic and bipolar I disorders in a general population. Arch. Gen. Psychiatry 64, 19-28. doi: 10.1001/archpsyc.64.1.19

Perrotta, C., Cervia, D., De Palma, C., Assi, E., Pellegrino, P., Bassi, M. T., et al. (2015). The emerging role of acid sphingomyelinase in autophagy. Apoptosis 20, 635-644. doi: 10.1007/s10495-015-1101-9

Phiel, C. J., and Klein, P. S. (2001). Molecular targets of lithium action. Annu. Rev. Pharmacol. Toxicol. 41, 789-813. doi: 10.1146/annurev.pharmtox.41.1.789

Pickford, F., Masliah, E., Britschgi, M., Lucin, K., Narasimhan, R., Jaeger, P. A., et al. (2008). The autophagy-related protein beclin 1 shows reduced expression in early Alzheimer disease and regulates amyloid beta accumulation in mice. J. Clin. Investig. 118, 2190-2199. doi: 10.1172/Jci33585

Puyal, J., and Clarke, P. G. (2009). Targeting autophagy to prevent neonatal stroke damage. Autophagy 5, 1060-1061. doi: 10.4161/auto.5.7.9728

Puyal, J., Ginet, V., Grishchuk, Y., Truttmann, A. C., and Clarke, P. G. (2012). Neuronal autophagy as a mediator of life and death: contrasting roles in chronic neurodegenerative and acute neural disorders. Neuroscientist 18, 224-236. doi: $10.1177 / 1073858411404948$

Qin, Z. H., Wang, Y., Kegel, K. B., Kazantsev, A., Apostol, B. L., Thompson, L. M., et al. (2003). Autophagy regulates the processing of amino terminal huntingtin fragments. Hum. Mol. Genet. 12, 3231-3244. doi: 10.1093/hmg/ddg346

Racagni, G., and Popoli, M. (2008). Cellular and molecular mechanisms in the long-term action of antidepressants. Dialogues Clin. Neurosci. 10, 385-400.

Ravikumar, B., Acevedo-Arozena, A., Imarisio, S., Berger, Z., Vacher, C., O’Kane, C. J., et al. (2005). Dynein mutations impair autophagic clearance of aggregateprone proteins. Nat. Genet. 37, 771-776. doi: 10.1038/ng1591

Ravikumar, B., Berger, Z., Vacher, C., O'Kane, C. J., and Rubinsztein, D. C. (2006). Rapamycin pre-treatment protects against apoptosis. Hum. Mol. Genet. 15, 1209-1216. doi: $10.1093 / \mathrm{hmg} / \mathrm{ddl} 036$

Ravikumar, B., Duden, R., and Rubinsztein, D. C. (2002). Aggregate-prone proteins with polyglutamine and polyalanine expansions are degraded by autophagy. Hum. Mol. Genet. 11, 1107-1117. doi: 10.1093/hmg/11.9. 1107

Ravikumar, B., Vacher, C., Berger, Z., Davies, J. E., Luo, S., Oroz, L. G., et al. (2004). Inhibition of mTOR induces autophagy and reduces toxicity of polyglutamine expansions in fly and mouse models of Huntington disease. Nat. Genet. 36, 585-595. doi: 10.1038/ng1362

Renna, M., Jimenez-Sanchez, M., Sarkar, S., and Rubinsztein, D. C. (2010). Chemical inducers of autophagy that enhance the clearance of mutant proteins in neurodegenerative diseases. J. Biol. Chem. 285, 11061-11067. doi: 10.1074/ jbc.R109.072181

Rezin, G. T., Amboni, G., Zugno, A. I., Quevedo, J., and Streck, E. L. (2009). Mitochondrial dysfunction and psychiatric disorders. Neurochem. Res. 34, 1021-1029. doi: 10.1007/s11064-008-9865-8

Ross, C. A., and Poirier, M. A. (2004). Protein aggregation and neurodegenerative disease. Nat. Med. 10(Suppl.), S10-S17. doi: 10.1038/nm1066

Rubinsztein, D. C., Codogno, P., and Levine, B. (2012). Autophagy modulation as a potential therapeutic target for diverse diseases. Nat. Rev. Drug Discov. 11, 709-730. doi: $10.1038 / \mathrm{nrd} 3802$

Rubinsztein, D. C., Cuervo, A. M., Ravikumar, B., Sarkar, S., Korolchuk, V. Kaushik, S., et al. (2009). In search of an "autophagomometer". Autophagy 5, 585-589. doi: 10.4161/auto.5.5.8823 
Rubinsztein, D. C., DiFiglia, M., Heintz, N., Nixon, R. A., Qin, Z. H., Ravikumar, B., et al. (2005). Autophagy and its possible roles in nervous system diseases, damage and repair. Autophagy 1, 11-22. doi: 10.4161/auto.1.1.1513

Rubinsztein, D. C., Gestwicki, J. E., Murphy, L. O., and Klionsky, D. J. (2007). Potential therapeutic applications of autophagy. Nat. Rev. Drug Discov. 6, 304-312. doi: 10.1038/nrd2272

Rusmini, P., Cortese, K., Crippa, V., Cristofani, R., Cicardi, M. E., Ferrari, V., et al. (2018). Trehalose induces autophagy via lysosomal-mediated TFEB activation in models of motoneuron degeneration. Autophagy 15, 631-651. doi: 10.1080/ 15548627.2018.1535292

Sade, Y., Toker, L., Kara, N. Z., Einat, H., Rapoport, S., Moechars, D., et al. (2016). IP3 accumulation and/or inositol depletion: two downstream lithium's effects that may mediate its behavioral and cellular changes. Transl. Psychiatry 6:e968. doi: $10.1038 /$ tp. 2016.217

Samara, C., Syntichaki, P., and Tavernarakis, N. (2008). Autophagy is required for necrotic cell death in Caenorhabditis elegans. Cell Death Differ. 15, 105-112. doi: $10.1038 /$ sj.cdd.4402231

Sapp, E., Penney, J., Young, A., Aronin, N., Vonsattel, J. P., and DiFiglia, M. (1999). Axonal transport of N-terminal huntingtin suggests early pathology of corticostriatal projections in Huntington disease. J. Neuropathol. Exp. Neurol. 58, 165-173. doi: 10.1097/00005072-199902000-00006

Sarkar, S., Davies, J. E., Huang, Z., Tunnacliffe, A., and Rubinsztein, D. C. (2007a). Trehalose, a novel mTOR-independent autophagy enhancer, accelerates the clearance of mutant huntingtin and alpha-synuclein. J. Biol. Chem. 282, 5641-5652. doi: 10.1074/jbc.M609532200

Sarkar, S., Perlstein, E. O., Imarisio, S., Pineau, S., Cordenier, A., Maglathlin, R. L., et al. (2007b). Small molecules enhance autophagy and reduce toxicity in Huntington's disease models. Nat. Chem. Biol. 3, 331-338. doi: 10.1038/ nchembio883

Sarkar, S., Floto, R. A., Berger, Z., Imarisio, S., Cordenier, A., Pasco, M., et al. (2005). Lithium induces autophagy by inhibiting inositol monophosphatase. J. Cell Biol. 170, 1101-1111. doi: 10.1083/jcb.200504035

Sarkar, S., Krishna, G., Imarisio, S., Saiki, S., O’Kane, C. J., and Rubinsztein, D. C. (2008). A rational mechanism for combination treatment of Huntington's disease using lithium and rapamycin. Hum. Mol. Genet. 17, 170-178. doi: 10. 1093/hmg/ddm 294

Sarkar, S., and Rubinsztein, D. C. (2006). Inositol and IP3 levels regulate autophagy: biology and therapeutic speculations. Autophagy 2, 132-134. doi: 10.4161/auto. 2387

Sasaki, T., Han, F., Shioda, N., Moriguchi, S., Kasahara, J., Ishiguro, K., et al. (2006). Lithium-induced activation of Akt and CaM kinase II contributes to its neuroprotective action in a rat microsphere embolism model. Brain Res. 1108, 98-106. doi: 10.1016/j.brainres.2006.06.009

Scaini, G., Rezin, G. T., Carvalho, A. F., Streck, E. L., Berk, M., and Quevedo, J. (2016). Mitochondrial dysfunction in bipolar disorder: evidence, pathophysiology and translational implications. Neurosci. Biobehav. Rev. 68, 694-713. doi: 10.1016/j.neubiorev.2016.06.040

Scott, R. C., Juhasz, G., and Neufeld, T. P. (2007). Direct induction of autophagy by Atg1 inhibits cell growth and induces apoptotic cell death. Curr. Biol. 17, 1-11. doi: $10.1016 /$ j.cub.2006.10.053

Scrivo, A., Bourdenx, M., Pampliega, O., and Cuervo, A. M. (2018). Selective autophagy as a potential therapeutic target for neurodegenerative disorders. Lancet Neurol. 17, 802-815. doi: 10.1016/S1474-4422(18)30238-2

Settembre, C., and Ballabio, A. (2011). TFEB regulates autophagy: an integrated coordination of cellular degradation and recycling processes. Autophagy 7, 1379-1381. doi: 10.4161/auto.7.11.17166

Shelton, R. C., Claiborne, J., Sidoryk-Wegrzynowicz, M., Reddy, R., Aschner, M., Lewis, D. A., et al. (2011). Altered expression of genes involved in inflammation and apoptosis in frontal cortex in major depression. Mol. Psychiatry 16, 751762. doi: $10.1038 / \mathrm{mp} .2010 .52$

Shibata, M., Lu, T., Furuya, T., Degterev, A., Mizushima, N., Yoshimori, T., et al. (2006). Regulation of intracellular accumulation of mutant huntingtin by beclin 1. J. Biol. Chem. 281, 14474-14485. doi: 10.1074/jbc.M600 364200

Shintani, T., and Klionsky, D. J. (2004). Autophagy in health and disease: a double-edged sword. Science 306, 990-995. doi: 10.1126/science.1099993

Simoncini, C., Orsucci, D., Caldarazzo Ienco, E., Siciliano, G., Bonuccelli, U., and Mancuso, M. (2015). Alzheimer's pathogenesis and its link to the mitochondrion. Oxid. Med. Cell. Longev. 2015:803942. doi: 10.1155/2015/ 803942

Son, J. H., Shim, J. H., Kim, K. H., Ha, J. Y., and Han, J. Y. (2012). Neuronal autophagy and neurodegenerative diseases. Exp. Mol. Med. 44, 89-98. doi: 10.3858/emm.2012.44.2.031

Spilman, P., Podlutskaya, N., Hart, M. J., Debnath, J., Gorostiza, O., Bredesen, D., et al. (2010). Inhibition of mTOR by rapamycin abolishes cognitive deficits and reduces amyloid-beta levels in a mouse model of Alzheimer's disease. PLoS One 5:e9979. doi: 10.1371/journal.pone.0009979

Stambolic, V., Ruel, L., and Woodgett, J. R. (1996). Lithium inhibits glycogen synthase kinase-3 activity and mimics wingless signalling in intact cells. Curr. Biol. 6, 1664-1668.

Stoka, V., Turk, V., and Turk, B. (2016). Lysosomal cathepsins and their regulation in aging and neurodegeneration. Ageing Res. Rev. 32, 22-37. doi: 10.1016/j.arr. 2016.04.010

Takahashi, S., Cui, Y. H., Han, Y. H., Fagerness, J. A., Galloway, B., Shen, Y. C., et al. (2008). Association of SNPs and haplotypes in APOL1, 2 and 4 with schizophrenia. Schizophr. Res. 104, 153-164. doi: 10.1016/j.schres.2008.05.028

Tandon, R., Gaebel, W., Barch, D. M., Bustillo, J., Gur, R. E., Heckers, S., et al. (2013). Definition and description of schizophrenia in the DSM-5. Schizophr. Res. 150, 3-10. doi: 10.1016/j.schres.2013.05.028

Tanida, I., Ueno, T., and Kominami, E. (2008). LC3 and autophagy. Methods Mol. Biol. 445, 77-88. doi: 10.1007/978-1-59745-157-4_4

Taylor, J. P., Hardy, J., and Fischbeck, K. H. (2002). Toxic proteins in neurodegenerative disease. Science 296, 1991-1995. doi: 10.1126/science. 1067122

Tellez-Nagel, I., Johnson, A. B., and Terry, R. D. (1974). Studies on brain biopsies of patients with Huntington's chorea. J. Neuropathol. Exp. Neurol. 33, 308-332. doi: 10.1097/00005072-197404000-00008

Terry, R. D., and Davies, P. (1980). Dementia of the Alzheimer type. Annu. Rev. Neurosci. 3, 77-95. doi: 10.1146/annurev.ne.03.030180.000453

The Huntington's Disease Collaborative Research Group (1993). A novel gene containing a trinucleotide repeat that is expanded and unstable on Huntington's disease chromosomes. Cell 72, 971-983. doi: 10.1016/0092-8674(93)90585-e

Thoreen, C. C., Kang, S. A., Chang, J. W., Liu, Q., Zhang, J., Gao, Y., et al. (2009). An ATP-competitive mammalian target of rapamycin inhibitor reveals rapamycin-resistant functions of mTORC1. J. Biol. Chem. 284, 8023-8032. doi: 10.1074/jbc.M900301200

Toker, L., and Agam, G. (2014). Lithium, inositol and mitochondria. ACS Chem. Neurosci. 5, 411-412. doi: 10.1021/cn5001149

Toker, L., and Agam, G. (2015). Mitochondrial dysfunction in psychiatric morbidity: current evidence and therapeutic prospects. Neuropsychiatr. Dis. Treat. 11, 2441-2447. doi: 10.2147/NDT.S70346

Toker, L., Bersudsky, Y., Plaschkes, I., Chalifa-Caspi, V., Berry, G. T., Buccafusca, R., et al. (2014). Inositol-related gene knockouts mimic lithium's effect on mitochondrial function. Neuropsychopharmacology 39, 319-328. doi: 10.1038/ npp.2013.194

Uchiyama, Y., Koike, M., Shibata, M., and Sasaki, M. (2009). Autophagic neuron death. Methods Enzymol. 453, 33-51. doi: 10.1016/S0076-6879(08)04003-2

Uttenweiler, A., and Mayer, A. (2008). Microautophagy in the yeast Saccharomyces cerevisiae. Methods Mol. Biol. 445, 245-259. doi: 10.1007/978-1-59745-157-4_16

Verhoef, L. G., Lindsten, K., Masucci, M. G., and Dantuma, N. P. (2002). Aggregate formation inhibits proteasomal degradation of polyglutamine proteins. Hum. Mol. Genet. 11, 2689-2700. doi: 10.1093/hmg/11.22.2689

Vodicka, P., Chase, K., Iuliano, M., Tousley, A., Valentine, D. T., Sapp, E., et al. (2016). Autophagy activation by transcription factor EB (TFEB) in striatum of HDQ175/Q7 mice. J. Huntingtons Dis. 5, 249-260. doi: 10.3233/JHD160211

Vulih-Shultzman, I., Pinhasov, A., Mandel, S., Grigoriadis, N., Touloumi, O., Pittel, Z., et al. (2007). Activity-dependent neuroprotective protein snippet NAP reduces tau hyperphosphorylation and enhances learning in a novel transgenic mouse model. J. Pharmacol. Exp. Ther. 323, 438-449. doi: 10.1124/jpet.107. 129551

Wainwright, S. R., and Galea, L. A. (2013). The neural plasticity theory of depression: assessing the roles of adult neurogenesis and PSA-NCAM within the hippocampus. Neural Plast. 2013:805497. doi: 10.1155/2013/ 805497 
Wang, J. F. (2007). Defects of mitochondrial electron transport chain in bipolar disorder: implications for mood-stabilizing treatment. Can. J. Psychiatry 52, 753-762. doi: 10.1177/070674370705201202

Wang, P. S., Simon, G., and Kessler, R. C. (2003). The economic burden of depression and the cost-effectiveness of treatment. Int. J. Methods Psychiatr. Res. $12,22-33$.

Wang, Q. J., Ding, Y., Kohtz, D. S., Mizushima, N., Cristea, I. M., Rout, M. P., et al. (2006). Induction of autophagy in axonal dystrophy and degeneration. J. Neurosci. 26, 8057-8068. doi: 10.1523/JNEUROSCI.2261-06.2006

Webb, J. L., Ravikumar, B., Atkins, J., Skepper, J. N., and Rubinsztein, D. C. (2003). Alpha-Synuclein is degraded by both autophagy and the proteasome. J. Biol. Chem. 278, 25009-25013. doi: 10.1074/jbc.M300227200

Wei, K., Wang, P., and Miao, C. Y. (2012). A double-edged sword with therapeutic potential: an updated role of autophagy in ischemic cerebral injury. CNS Neurosci. Ther. 18, 879-886. doi: 10.1111/cns.12005

Whyte, L. S., Lau, A. A., Hemsley, K. M., Hopwood, J. J., and Sargeant, T. J. (2017). Endo-lysosomal and autophagic dysfunction: a driving factor in Alzheimer's disease? J. Neurochem. 140, 703-717. doi: 10.1111/jnc.13935

Williams, A., Jahreiss, L., Sarkar, S., Saiki, S., Menzies, F. M., Ravikumar, B., et al. (2006). Aggregate-prone proteins are cleared from the cytosol by autophagy: therapeutic implications. Curr. Top. Dev. Biol. 76, 89-101. doi: 10.1016/S00702153(06)76003-3

Williams, A., Sarkar, S., Cuddon, P., Ttofi, E. K., Saiki, S., Siddiqi, F. H., et al. (2008). Novel targets for Huntington's disease in an mTOR-independent autophagy pathway. Nat. Chem. Biol. 4, 295-305. doi: 10.1038/nchembio.79

Williams, R. S., Cheng, L., Mudge, A. W., and Harwood, A. J. (2002). A common mechanism of action for three mood-stabilizing drugs. Nature 417, 292-295. doi: 10.1038/417292a

Winslow, A. R., Chen, C. W., Corrochano, S., Acevedo-Arozena, A., Gordon, D. E., Peden, A. A., et al. (2010). alpha-Synuclein impairs macroautophagy: implications for Parkinson's disease. J. Cell Biol. 190, 1023-1037. doi: 10.1083/ jcb.201003122

Winslow, A. R., and Rubinsztein, D. C. (2008). Autophagy in neurodegeneration and development. Biochim. Biophys. Acta 1782, 723-729. doi: 10.1016/j.bbadis. 2008.06.010

Wong, E., and Cuervo, A. M. (2010). Autophagy gone awry in neurodegenerative diseases. Nat. Neurosci. 13, 805-811. doi: 10.1038/nn.2575

Wu, H., Chen, S., Ammar, A. B., Xu, J., Wu, Q., Pan, K., et al. (2015). Crosstalk between macroautophagy and chaperone-mediated autophagy: implications for the treatment of neurological diseases. Mol. Neurobiol. 52, 1284-1296. doi: 10.1007/s12035-014-8933-0

Wu, Y., Li, X., Zhu, J. X., Xie, W., Le, W., Fan, Z., et al. (2011). Resveratrol-activated AMPK/SIRT1/autophagy in cellular models of Parkinson's disease. Neurosignals 19, 163-174. doi: 10.1159/000328516

Xue, L., Fletcher, G. C., and Tolkovsky, A. M. (1999). Autophagy is activated by apoptotic signalling in sympathetic neurons: an alternative mechanism of death execution. Mol. Cell. Neurosci. 14, 180-198. doi: 10.1006/mcne.1999. 0780

Yamamoto, A., Cremona, M. L., and Rothman, J. E. (2006). Autophagy-mediated clearance of huntingtin aggregates triggered by the insulin-signaling pathway. J. Cell Biol. 172, 719-731. doi: 10.1083/jcb.200510065

Yamamoto, A., Lucas, J. J., and Hen, R. (2000). Reversal of neuropathology and motor dysfunction in a conditional model of Huntington's disease. Cell 101, 57-66. doi: 10.1016/S0092-8674(00)80623-6

Yamamoto, A., and Yue, Z. (2014). Autophagy and its normal and pathogenic states in the brain. Annu. Rev. Neurosci. 37, 55-78. doi: 10.1146/annurev-neuro071013-014149

Yang, C., Zhou, Z. Q., Gao, Z. Q., Shi, J. Y., and Yang, J. J. (2013). Acute increases in plasma mammalian target of rapamycin, glycogen synthase kinase-3beta, and eukaryotic elongation factor 2 phosphorylation after ketamine treatment in three depressed patients. Biol. Psychiatry 73, e35-e36. doi: 10.1016/j.biopsych. 2012.07.022

Yang, D. S., Stavrides, P., Mohan, P. S., Kaushik, S., Kumar, A., Ohno, M., et al. (2011). Reversal of autophagy dysfunction in the TgCRND8 mouse model of Alzheimer's disease ameliorates amyloid pathologies and memory deficits. Brain 134(Pt 1), 258-277. doi: 10.1093/brain/awq341

Yang, Y., Fukui, K., Koike, T., and Zheng, X. (2007). Induction of autophagy in neurite degeneration of mouse superior cervical ganglion neurons. Eur. J. Neurosci. 26, 2979-2988. doi: 10.1111/j.1460-9568.2007.05914.x

Yu, W. H., Cuervo, A. M., Kumar, A., Peterhoff, C. M., Schmidt, S. D., Lee, J. H., et al. (2005). Macroautophagy-a novel Beta-amyloid peptide-generating pathway activated in Alzheimer's disease. J. Cell Biol. 171, 87-98. doi: 10.1083/ jcb.200505082

Yu, W. H., Kumar, A., Peterhoff, C., Shapiro Kulnane, L., Uchiyama, Y., Lamb, B. T., et al. (2004). Autophagic vacuoles are enriched in amyloid precursor protein-secretase activities: implications for beta-amyloid peptide over-production and localization in Alzheimer's disease. Int. J. Biochem. Cell Biol. 36, 2531-2540. doi: 10.1016/j.biocel.2004.05.010

Yuan, J., Song, J., Zhu, D., Sun, E., Xia, L., Zhang, X., et al. (2018). Lithium treatment is safe in children with intellectual disability. Front. Mol. Neurosci. 11:425. doi: 10.3389/fnmol.2018.00425

Yuan, Y., Wang, H., Wei, Z., and Li, W. (2015). Impaired autophagy in hilar mossy cells of the dentate gyrus and its implication in schizophrenia. J. Genet. Genomics 42, 1-8. doi: 10.1016/j.jgg.2014.12.001

Yue, Z. (2014). Regulation of neuronal autophagy in axon: implication of autophagy in axonal function and dysfunction/degeneration. Autophagy 3, 139-141. doi: 10.4161/auto.3602

Zarate, C. A. Jr., Singh, J., and Manji, H. K. (2006a). Cellular plasticity cascades: targets for the development of novel therapeutics for bipolar disorder. Biol. Psychiatry 59, 1006-1020. doi: 10.1016/j.biopsych.2005.10.021

Zarate, C. A. Jr., Singh, J. B., Carlson, P. J., Brutsche, N. E., Ameli, R., Luckenbaugh, D. A., et al. (2006b). A randomized trial of an N-methyl-D-aspartate antagonist in treatment-resistant major depression. Arch. Gen. Psychiatry 63, 856-864. doi: 10.1001/archpsyc.63.8.856

Zhang, Y., Chen, X., Zhao, Y., Ponnusamy, M., and Liu, Y. (2017). The role of ubiquitin proteasomal system and autophagy-lysosome pathway in Alzheimer's disease. Rev. Neurosci. 28, 861-868. doi: 10.1515/revneuro2017-0013

Zhaorigetu, S., Wan, G., Kaini, R., Jiang, Z., and Hu, C. A. (2008). ApoL1, a BH3-only lipid-binding protein, induces autophagic cell death. Autophagy 4, 1079-1082. doi: 10.4161/auto.7066

Zhu, J. H., Guo, F., Shelburne, J., Watkins, S., and Chu, C. T. (2003). Localization of phosphorylated ERK/MAP kinases to mitochondria and autophagosomes in Lewy body diseases. Brain Pathol. 13, 473-481. doi: 10.1111/j.1750-3639.2003. tb00478.x

Zschocke, J., and Rein, T. (2011). Antidepressants encounter autophagy in neural cells. Autophagy 7, 1247-1248. doi: 10.4161/auto.7.10.16520

Conflict of Interest Statement: The authors declare that the research was conducted in the absence of any commercial or financial relationships that could be construed as a potential conflict of interest.

Copyright (c) 2019 Bar-Yosef, Damri and Agam. This is an open-access article distributed under the terms of the Creative Commons Attribution License (CC BY). The use, distribution or reproduction in other forums is permitted, provided the original author(s) and the copyright owner(s) are credited and that the original publication in this journal is cited, in accordance with accepted academic practice. No use, distribution or reproduction is permitted which does not comply with these terms. 